\title{
Normalized Earthquake Damage and Fatalities in the United States: 1900-2005
}

\author{
Kevin Vranes ${ }^{1}$ and Roger Pielke $\mathrm{Jr}^{2}$
}

\begin{abstract}
Damage estimates from 80 U.S. earthquakes since 1900 are "normalized" to 2005 dollars by adjusting for inflation, increases in wealth, and changes in population. Factors accounting for mitigation at 1 and $2 \%$ loss reduction per year are also considered. The earthquake damage record is incomplete, perhaps by up to $25 \%$ of total events that cause damage, but all of the most damaging events are accounted for. For events with damage estimates, cumulative normalized losses since 1900 total $\$ 453$ billion, or $\$ 235$ billion and $\$ 143$ billion when 1 and 2\% mitigation is factored, respectively. The 1906 San Francisco earthquake and fire adjusts to \$39-\$328 billion depending on assumptions and mitigation factors used, likely the most costly natural disaster in U.S. history in normalized 2005 values. Since 1900, 13 events would have caused $\$ 1$ billion or more in losses had they occurred in 2005; five events adjust to more than $\$ 10$ billion in damages. Annual average losses range from $\$ 1.3$ billion to $\$ 5.7$ billion with an average across data sets and calculation methods of $\$ 2.5$ billion, below catastrophe model estimates and estimates of average annual losses from hurricanes. Fatalities are adjusted for population increase and mitigation, with five events causing over 100 fatalities when mitigation is not considered, four (three) events when $1 \%$ (2\%) mitigation is considered. Fatalities in the 1906 San Francisco event adjusts from 3,000 to over 24,000, or 8,900 (3,300) if $1 \%$ (2\%) mitigation is considered. Implications for comparisons of normalized results with catastrophe model output and with normalized damage profiles of other hazards are considered.
\end{abstract}

DOI: 10.1061/(ASCE)1527-6988(2009)10:3(84)

CE Database subject headings: Earthquakes; Damage; United States; Fatalities; History.

\section{Introduction}

Unlike many weather-related hazards, a comprehensive accounting of earthquake damage in the United States through time has yet to be compiled. Accurate understanding of trends in property damage requires accounting for societal factors that, in addition to earthquakes, shape economic losses. This paper contributes to a growing literature that seeks to "normalize" past disaster damage by accounting for societal change, as a complement to other approaches focused on modeling events and their losses.

This paper provides a normalization of earthquake losses in the United States and Puerto Rico. Damage estimates of earthquake events since 1900 are adjusted for changes in inflation, wealth, and population in the locales affected by earthquakes. A factor accounting for improvements in building standards is also considered. In addition, fatality data is adjusted for population increase, under several assumptions about the effectiveness of mitigation, providing a noneconomic metric by which to compare various disasters.

\footnotetext{
${ }^{1}$ Principal Consultant, Point380 LLC, 1375 Walnut St., Boulder, CO 80302 (corresponding author). E-mail: kvranes@point380.com

${ }^{2}$ Professor, Center for Science and Technology Policy Research, Cooperative Institute for Research in the Environmental Sciences, 1333 Grandview Ave., Campus Box 488, Univ. of Colorado, Boulder, CO 80309. E-mail: pielke@ colorado.edu

Note. This manuscript was submitted on July 5, 2006; approved on July 9, 2008; published online on July 15, 2009. Discussion period open until January 1, 2010; separate discussions must be submitted for individual papers. This paper is part of the Natural Hazards Review, Vol. 10, No. 3, August 1, 2009. CASCE, ISSN 1527-6988/2009/3-84-101/ $\$ 25.00$.
}

\section{Normalization Methodologies}

Pielke et al. (2008) describe the goals of disaster loss normalization as applied to historical hurricane damage as follows: "to provide longitudinally consistent estimates of the economic damage that past storms would have had under contemporary levels of population and development." The logic of normalization is straightforward: two identical structures will experience twice the damage of a single structure for a given geophysical event. Over time, normalization becomes more complicated because loss data are influenced by a number of important societal factors, including changes in the number of properties and the value of their contents, as well as efforts to mitigate losses through changing building practices and codes. Catastrophe models are one important tool that have been developed to assess potential losses in the face of changing exposure and vulnerability, in the context of various geophysical events. Normalized losses provide an independent basis of loss estimation for comparison with catastrophe models and have been recommended within the insurance industry as a valuable contribution to loss estimation (e.g., Collins and Lowe 2001).

Normalization methodologies have been applied to weatherrelated hazards in a wide range of contexts. Pielke et al. (2008) normalize U.S. hurricane losses over 2000-2005, providing an update to two earlier studies (Pielke and Landsea 1998; Collins and Lowe 2001). Pielke et al. (2006) also provide another independent estimate of normalized U.S. hurricane losses based on a data set compiled by Munich Re insurance. Brooks and Doswell (2001) normalize major tornado losses from 1890 to 1999. Pielke et al. (2003) estimate 20th century normalized hurricane losses for Cuba and selected events in Latin America and the Caribbean. P. Crompton and K. J. McAneney ("Trends in Australian insured 
losses due to natural hazards," Environmental Science and Policy, in review) provide normalized loss estimates for weather-related hazards in Australia from 1966 to 2005. Raghavan and Rajesh (2003) provide normalized tropical cyclone losses for the Andhra Pradesh region of India. To date, such methods have not been applied to U.S. earthquake losses.

But do normalization approaches to loss estimation provide valuable information on loss potentials? Several studies have provided rigorous tests of normalized losses suggesting that the methodology is capable of adjusting effectively for societal factors related to losses. For example, using the data set developed by Pielke and Landsea (1998), Katz (2002) found in the normalized loss data the presence of a climatological signal of the El Niño-Southern Oscillation which has a strong effect on Atlantic hurricane activity. Pielke et al. (2008) found trends in normalized U.S. hurricane losses match trends in the climatology of hurricane landfalls, concluding

This finding should add some confidence that, at least to a first degree, the normalization approach has successfully adjusted for changing societal conditions. Given the lack of trends in hurricanes themselves, any trend observed in the normalized losses would necessarily reflect some bias in the adjustment process, such as failing to recognize changes in adaptive capacity or misspecifying wealth. That we do not have a resulting bias suggests that any factors not included in the normalization methods do not have a resulting net large significance.

Thus, one effective approach to evaluating the results of a disaster normalization is to compare the resulting statistical characteristics of the distribution of losses with those of the geophysical phenomena that causes losses. Because the goal of disaster loss normalization is to remove the signal of societal change in the loss data, at a minimum an effectively adjusted data set should reflect the statistical characteristics of geophysical events better than a nonadjusted data set.

\section{Earthquake Data}

Property damage estimates from earthquakes are scattered among hundreds of sources and collated in three databases of varying comprehensiveness. This factor alone means that a normalization of historical earthquake losses is likely to be subject to a greater degree of uncertainty than comparable data sets related to weather disasters which have been collected by single agencies using consistent methodologies (e.g., Downton and Pielke 2005).

The main database used for this research is the Significant Earthquake Database (NGDC-s) published by the National Geophysical Data Center (Dunbar et al. 2006). Each NGDC-s record is listed with at least one source and in some cases many sources. Earthquakes listed in NGDC-s that occurred prior to the 1980's generally draw on Stover and Coffman (1993), Coffman et al. (1982) or other serial reports of the United States Geological Survey (USGS). Like all of the data sets with damage estimates, the information in NGDC-s is sparse before 1970 [Fig. 1(a)]. Some NGDC-s records cite EM-DAT (2006) as a primary source, but Stover and Coffman (1993) is the most complete source used.

The SHELDUS database is a product of the Hazards Research Lab of the University of South Carolina (Cutter and Emrich 2005; Hazards Research Lab 2006). In most cases SHELDUS uses the NGDC-s value or the most conservative value if multiple num-

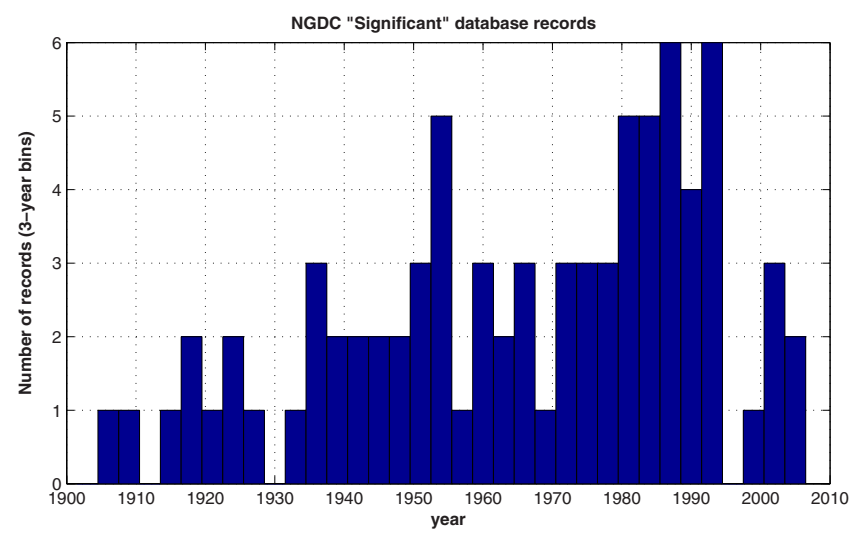

(a)

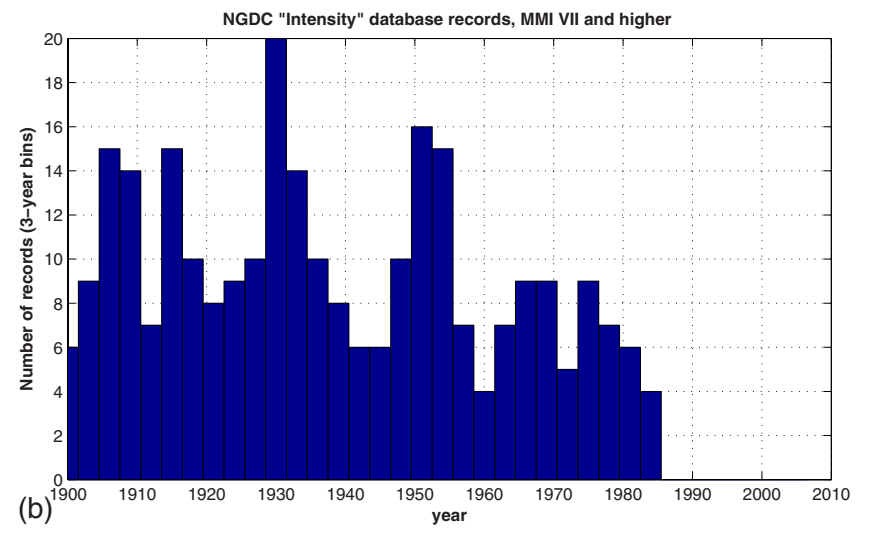

Fig. 1. Distribution of events in the NGDC-s and NGDC-i databases in 3-year bins beginning 1900-1902

bers are given by NGDC-s, but in a few cases SHELDUS and NGDC-s disagree or SHELDUS lists a damage estimate that does not match the lowest NGDC-s estimate. In such cases the SHELDUS value is based on other published reports (M. Gall, personal communication, April 2006). SHELDUS contains data only since 1960.

EM-DAT (2006) is a disasters database of the Center for Research on the Epidemiology of Disasters (CRED) at the Université Catholique de Louvain in Brussels, Belgium. Its coverage is much less extensive than NGDC-s, and EM-DAT does not contain any events not also contained by either SHELDUS or NGDC-s, but EM-DAT often lists damage estimates different than NGDC-s. CRED claims that all data in EM-DAT comes from a variety of sources, "including governmental and nongovernmental agencies, insurance companies, research institutes, and press agencies" and that validation procedures are in place. Citation information for individual events is not readily available, however, making it impossible to evaluate the original source for loss information. Further, when comparing EM-DAT records with NGDC records there is an almost systematic elevation of estimated losses in the EMDAT report.

The most comprehensive descriptive catalog of U.S. seismicity is Stover and Coffman (1993), which is not available electronically and ends in 1989. Stover and Coffman (1993) was scanned thoroughly as a check on the NGDC-s, SHELDUS and EMDAT databases. Twenty additional events with estimated property losses were found in Stover and Coffman (1993) that do not appear in any of the databases, and thirteen events were found with estimated damages differing from the database sources. 


\begin{tabular}{|c|c|c|c|c|c|c|c|}
\hline $\begin{array}{l}\text { Common } \\
\text { event name }\end{array}$ & Date & Location & $\begin{array}{c}\text { Est. } \\
\text { losses } \\
\text { (event year) } \\
(\$)\end{array}$ & $\begin{array}{l}\text { Inflation- } \\
\text { adjusted } \\
\text { losses } \\
(\$)\end{array}$ & $\begin{array}{c}\text { Normalized } \\
\text { damages } \\
\text { (no mitigation) } \\
(\$)\end{array}$ & $\begin{array}{c}\text { Normalized } \\
\text { damages } \\
(1 \% \text { mitigation }) \\
(\$)\end{array}$ & $\begin{array}{c}\begin{array}{c}\text { Normalized } \\
\text { damages }\end{array} \\
(2 \% \text { mitigation }) \\
(\$)\end{array}$ \\
\hline San Francisco $^{\mathrm{a}}$ & April 18, 1906 & San Francisco Bay Area, Calif. & 524 & 8,942 & 283,735 & 104,905 & 38,397 \\
\hline Northridge & January 17, 1994 & Los Angeles metro area, Calif. & 47,350 & 58,815 & 87,381 & 78,235 & 69,968 \\
\hline Good Friday & March 28, 1964 & Southern Alaska, Anchorage area & 540 & 2,736 & 16,932 & 11,213 & 7,395 \\
\hline Long Beach & March 11, 1933 & Los Angeles metro area, Calif. & 39 & 496 & 15,599 & 7,565 & 3,642 \\
\hline Loma Prieta & October 18, 1989 & San Francisco Bay Area, Calif. & 5,750 & 8,206 & 12,315 & 10,485 & 8,913 \\
\hline San Fernando Valley & February 9, 1971 & Los Angeles metro area, Calif. & 540 & 2,092 & 7,155 & 5,084 & 3,600 \\
\hline Olympia & April 13, 1949 & Olympia, Wash. & 53 & 360 & 5,975 & 3,404 & 1,928 \\
\hline Mona Passage & October 11, 1918 & Puerto Rico & 29 & 262 & 4,660 & 1,944 & 804 \\
\hline Kern County & July 21, 1952 & Kern County, Calif. & 55 & 342 & 3,102 & 1,821 & 1,063 \\
\hline Santa Barbara & June 29, 1925 & Santa Barbara, Calif. & 8 & 74 & 3,066 & 1,372 & 609 \\
\hline Nisqually & February 28, 2001 & Seattle/Olympia areas, Wash. & 2,000 & 2,190 & 2,476 & 2,378 & 2,284 \\
\hline Bakersfield & August 22, 1952 & Kern County, Calif. & 20 & 124 & 1,128 & 662 & 387 \\
\hline Helena & October 31,1935 & Helena, Mont. & 6 & 70 & 1,035 & 512 & 252 \\
\hline Whittier Narrows & October 1,1987 & Los Angeles metro area, Calif. & 354 & 542 & 954 & 796 & 663 \\
\hline Imperial Valley & May 19, 1940 & Southern California/Mexico & 6 & 69 & 753 & 392 & 202 \\
\hline Terminal Island & November 18, 1949 & Los Angeles metro area, Calif. & 9 & 62 & 728 & 415 & 235 \\
\hline Hegben Lake & August 18, 1959 & Hegben Lake/southeastern Mont. & 4 & 41 & 604 & 299 & 147 \\
\hline
\end{tabular}

${ }^{\mathrm{a}}$ Normalization uses SF CSA for population correction (8.02, see text for explanation).

Other electronic data sources carry more limited earthquake damage information, and were used as a reference for events that carried multiple damage estimates. The California Geological Survey (CAGS 2009) makes available a Significant California Earthquakes list. Since it is derived directly from Stover and Coffman (1993) and does not report every event given a property damage estimate by Stover and Coffman (1993), the CAGS list is useful only after 1989. Post-1989 citation information is not available. The Munich Re reinsurance company also makes available a disaster list (NATHAN) but it only describes the ten largest U.S. earthquakes and does not carry information independent of the other sources mentioned above. Literature sources were also consulted on various events and are cited where appropriate in Appendix I.

The data sets used report damage values for two Hawaiian tsunamis spawned by Alaskan earthquakes (April 1, 1946, Unimak Island and March 9, 1957, Andreanof Islands). Because damages are reported only for the tsunami effects in Hawaii they are not included in the calculations reported in the text or in Tables 1-4, but they are listed in Appendix II. Curiously, although extensive infrastructure damage was reported in Alaska in the 1957 event, aside from Hawaiian tsunami damages (\$5 million), we located no estimate of Alaskan damage losses.

Among the data sets listed above, there are 64 unique events since 1900. Stover and Coffman (1993) provide damage estimates on an additional 16 events that do not appear in the databases, bringing the total number of events to 80 . Since there has never been a systematic methodology for determining total losses from an earthquake (NRC 1999), there is blurry separation between direct and indirect damage throughout the record. Further, many events have multiple estimates of damage. Where different sources provided conflicting damage estimates, three lists are derived from the 80-event list: a "high" list keeping only the highest damage estimate or the solitary estimate when only one is given; a "low" list keeping only the most conservative or solitary estimate; and a subjectively-determined "middle" list from the literature on each earthquake for which multiple damage estimates exist. In cases for which the literature provides no clear consensus, an average of available estimates is used. Appendix I contains a brief discussion of the events for which a "middle" value is derived. All available estimates are provided in Appendix II.

The average difference between the low and high estimates for the database, as a percentage of the low estimate, is $137 \%$. An analysis of flood damages across different sources found differences in estimates varied with the size of the event, with smaller events having larger percentage differences and larger events having smaller percentage differences (Downton and Pielke 2005). The effect is opposite here: of the 80 events, the average percentage difference in the lower half (the 40 events with lowest reported damages) is $50 \%$ while for the upper half it is $189 \%$. Thus, estimates for individual events should be interpreted with caution, with an understanding that unique, original damage estimates for the same event could differ by a significant amount. Normalization of earthquake damages can be improved with a standardized and consistent approach to documenting damage, such as performed by the National Weather Service in context of floods and hurricanes (NRC 1999).

In addition to the four databases that contain property damage estimates, the National Geophysical Data Center publishes the Earthquake Intensity Database (NGDC-i, Dunbar 1985). NGDC-i does not include damage estimates, but does include Modified Mercalli Intensities (MMI), a descriptive assessment of earthquake effects on a twelve-point scale (Wood and Neumann 1931), by convention denoted with Roman numerals. In general, any earthquake that achieves MMI of VIII should be associated with measurable economic losses; the largest quakes will achieve MMI of IX, X, and XI. The NGDC-i only contains data to 1985 but is more comprehensive than any of the other databases listed [Fig. 1(b)] so while it does not contain damage estimates, it provides a 


\begin{tabular}{|c|c|c|c|c|c|}
\hline & $\begin{array}{c}\text { Averaging } \\
\text { period }\end{array}$ & $\begin{array}{l}\text { Decade } \\
\text { count }\end{array}$ & $\begin{array}{c}\text { Average annual } \\
\text { losses } \\
\text { (no mitigation) } \\
(\$)\end{array}$ & $\begin{array}{c}\text { Average annual } \\
\text { losses } \\
(1 \% \text { mitigation }) \\
(\$)\end{array}$ & $\begin{array}{c}\text { Average annual } \\
\text { losses } \\
(2 \% \text { mitigation }) \\
(\$)\end{array}$ \\
\hline \multirow[t]{11}{*}{$\begin{array}{l}\text { ACC record (no 1906/1994) } \\
\text { (millions of } 2005 \text { dollars) }\end{array}$} & 1900-2005 & 2 & $\begin{array}{l}4,270 \\
(769)\end{array}$ & $\begin{array}{l}2,215 \\
(487)\end{array}$ & $\begin{array}{l}1,347 \\
(325)\end{array}$ \\
\hline & 1910-2005 & 3 & $\begin{array}{l}1,759 \\
(849)\end{array}$ & $\begin{array}{l}1,353 \\
(538)\end{array}$ & $\begin{array}{l}1,088 \\
(359)\end{array}$ \\
\hline & 1920-2005 & 4 & $\begin{array}{l}1,900 \\
(884)\end{array}$ & $\begin{array}{l}1,484 \\
(574)\end{array}$ & $\begin{array}{l}1,203 \\
(390)\end{array}$ \\
\hline & 1930-2005 & 5 & $\begin{array}{l}2,106 \\
(957)\end{array}$ & $\begin{array}{l}1,660 \\
(630)\end{array}$ & $\begin{array}{l}1,353 \\
(432)\end{array}$ \\
\hline & 1940-2005 & 7 & $\begin{array}{l}2,164 \\
(840)\end{array}$ & $\begin{array}{l}1,784 \\
(598)\end{array}$ & $\begin{array}{l}1,497 \\
(436)\end{array}$ \\
\hline & 1950-2005 & 10 & $\begin{array}{l}2,411 \\
(850)\end{array}$ & $\begin{array}{l}2,024 \\
(627)\end{array}$ & $\begin{array}{l}1,720 \\
(470)\end{array}$ \\
\hline & 1960-2005 & 8 & $\begin{array}{l}2,822 \\
(922)\end{array}$ & $\begin{array}{l}2,397 \\
(696)\end{array}$ & $\begin{array}{l}2,054 \\
(533)\end{array}$ \\
\hline & 1970-2005 & 9 & $\begin{array}{l}3,113 \\
(685)\end{array}$ & $\begin{array}{l}2,736 \\
(563)\end{array}$ & $\begin{array}{l}2,409 \\
(466)\end{array}$ \\
\hline & 1980-2005 & 18 & $\begin{array}{l}4,018 \\
(657)\end{array}$ & $\begin{array}{l}3,580 \\
(571)\end{array}$ & $\begin{array}{l}3,188 \\
(497)\end{array}$ \\
\hline & 1990-2005 & 8 & $\begin{array}{l}5,677 \\
(215)\end{array}$ & $\begin{array}{l}5,094 \\
(205)\end{array}$ & $\begin{array}{l}4,568 \\
(194)\end{array}$ \\
\hline & 2000-2005 & 6 & $\begin{array}{c}487 \\
(487)\end{array}$ & $\begin{array}{c}469 \\
(469)\end{array}$ & $\begin{array}{c}452 \\
(452)\end{array}$ \\
\hline
\end{tabular}

useful check to ensure that all major earthquakes are included in the damage list, and also a basis for comparing adjusted losses to the geophysical characteristics of past events. NGDC-i contains some records of events MMI VIII, IX, and X for which neither NGDC-s, EMDAT, nor SHELDUS list property damage estimates. Stover and Coffman (1993) also describe many events with Modified Mercalli Intensities of VIII, IX, and X for which estimated damages are not given. To ensure that all of the largest earthquakes are accounted for in this analysis, any event listed at MMI VIII or higher in NGDC-i with no damage estimate was investigated further, and the descriptions in Stover and Coffman (1993) were examined similarly. Most of these major seismic events occurred in sparsely-populated Alaska, Nevada, or Utah, with severe damage to only a small number of structures. In some cases significant economic losses probably occurred but were not given. These events are described in Appendix III, listing 27 events that likely caused significant damages. Although the earthquake property damage record is clearly incomplete, likely by at least $25 \%$ and especially for events occurring before the 1960's, we are confident that all of the most damaging U.S. earthquakes of the past century are accounted for.

\section{Normalizing Property Damage Data}

The normalization of past earthquake damage begins with three factors: inflation, wealth, and population, and then considers the effects of mitigation (cf. Crompton and McAneney, in review). All damages are normalized to 2005 values. Trends in the variables are displayed in Fig. 2.

\section{Inflation}

The inflation adjustment uses the implicit price deflator (IPD) for gross domestic product (GDP), available from the U.S. Bureau of Economic Analysis (BEA) for 1929-2005. For years before 1929, the GDP deflator of Johnston and Williamson (2006) is used. The Johnston and Williamson deflator draws on the work of multiple economic historians but is not considered as accurate as the official BEA deflator; Johnston and Williamson suggest that their analysis is accurate to two significant digits. An alternative statistic commonly used for inflation is the consumer price index (CPI), but the IPD is considered a more robust statistic for inflation as it does not rely on a fixed measurement of goods and services. Brooks and Doswell (2001) used CPI rather than IPD because at the time IPD was available only to 1940 .

\section{Wealth}

The wealth adjustment uses the BEA's fixed assets and consumer durable goods (FACDG) statistic, available for the period 1925-2005 (Table 1.1 of http://www.bea.gov/bea/dn/FAweb/ AllFATables.asp). In the absence of an available estimate for values before 1925, values to 1900 are extrapolated based on the 1925-1928 average change (a reduction of 3\% per year; Pielke et al. 2008). Fixed assets are defined as private and government assets such as equipment and structures. Consumer durable goods are nonbusiness goods purchased by households with a life expectancy of at least three years (Parker and Triplett 1995).

Like inflation, the FACDG is a national number with no local 
Table 3. Estimates for Normalized Annual Earthquake Losses by Data Set and Averaging Period (Millions of 2005 Dollars)

\begin{tabular}{|c|c|c|c|c|}
\hline & $\begin{array}{l}\text { Averaging } \\
\text { period }\end{array}$ & $\begin{array}{c}\text { No } \\
\text { mitigation }\end{array}$ & $\begin{array}{c}1 \% \\
\text { mitigation }\end{array}$ & $\begin{array}{c}2 \% \\
\text { mitigation }\end{array}$ \\
\hline \multirow{24}{*}{$\begin{array}{l}\text { NGDC-low } \\
\text { NGDC-high } \\
\text { SHELDUS } \\
\text { EMDAT } \\
\text { (millions of } \\
2005 \text { dollars) }\end{array}$} & \multirow[t]{4}{*}{ 1900-2005 } & 1,747 & 1,284 & 1,002 \\
\hline & & 4,438 & 2,313 & 1,403 \\
\hline & & - & - & - \\
\hline & & 3,921 & 1,843 & 979 \\
\hline & \multirow[t]{4}{*}{ 1960-2005 } & 2,933 & 2,463 & 2,087 \\
\hline & & 2,956 & 2,486 & 2,110 \\
\hline & & 1,796 & 1,466 & 1,212 \\
\hline & & 1,877 & 1,474 & 1,177 \\
\hline & \multirow[t]{4}{*}{ 1970-2005 } & 3,268 & 2,834 & 2,464 \\
\hline & & 3,278 & 2,846 & 2,477 \\
\hline & & 1,805 & 1,549 & 1,334 \\
\hline & & 1,482 & 1,278 & 1,107 \\
\hline & \multirow[t]{4}{*}{ 1980-2005 } & 3,986 & 3,528 & 3,121 \\
\hline & & 4,240 & 3,728 & 3,279 \\
\hline & & 2,285 & 1,992 & 1,739 \\
\hline & & 1,791 & 1,587 & 1,407 \\
\hline & \multirow[t]{4}{*}{ 1990-2005 } & 4,849 & 4,354 & 3,906 \\
\hline & & 4,710 & 4,239 & 3,812 \\
\hline & & 2,363 & 2,125 & 1,911 \\
\hline & & 2,136 & 1,924 & 1,732 \\
\hline & \multirow[t]{4}{*}{ 2000-2005 } & 567 & 546 & 525 \\
\hline & & 903 & 869 & 835 \\
\hline & & 434 & 417 & 400 \\
\hline & & 540 & 519 & 500 \\
\hline
\end{tabular}

information. The wealth numbers are adjusted for inflation and U.S. population to a per capita basis following (Pielke et al. 2008) in order to separate the independent effects on damage of changes in wealth over time. The per capita adjustment is used because

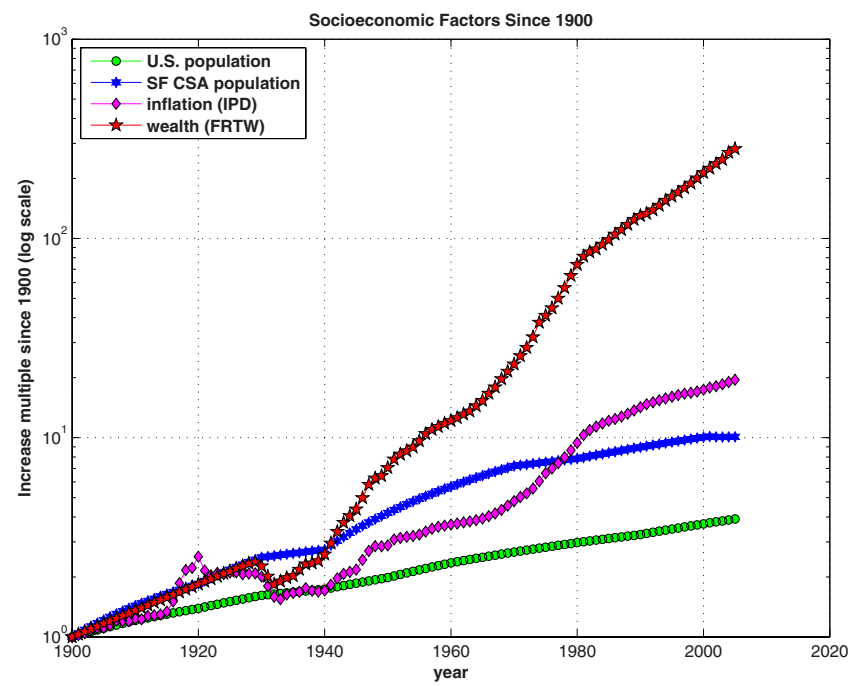

Fig. 2. Diamond symbols: changes in time since 1900 in inflation (implicit price deflator); star symbols: wealth (fixed reproducible tangible wealth); circle symbols: U.S. population; and star symbols: San Francisco combined statistical area population. The population changes are shown as examples; in the normalized record each event has a unique population adjustment.

while the increasing rate of wealth is population-dependent, wealth and population are not increasing at the same rate. The per capita wealth adjustment produces a more conservative estimate than using wealth changes adjusted for inflation alone (Fig. 2).

\section{Population}

The third adjustment factor used in this analysis is population change between the event year and 2005 in the areas affected by each earthquake, applied at the county level with intradecadal population estimates interpolated between the totals of the bracketing decades. While the inflation and wealth adjustments for each earthquake are fixed based on the year of the event and are thus straightforward in their application, the population correction introduces some challenges. Large earthquakes are usually regional

Table 4. Normalized (No Mitigation) Damage by Decade

\begin{tabular}{|c|c|c|c|c|c|c|c|c|c|}
\hline Year range & $\begin{array}{l}\text { Total } \\
\text { count }\end{array}$ & count $<\$ 100 \mathrm{M}$ & count $>\$ 100 \mathrm{M}$ & count $>\$ 500 \mathrm{M}$ & count $>\$ 1 B$ & count $>\$ 10 B$ & $\begin{array}{l}\text { Avg. damage } \\
\text { per yr } \\
(\$ M)\end{array}$ & $\begin{array}{c}\text { Total } \\
\text { damage } \\
(\$ M)\end{array}$ & $\begin{array}{c}\% \text { of total } \\
\text { damage } \\
(\%)\end{array}$ \\
\hline 1900-1909 & 2 & 1 & 1 & 1 & 1 & 1 & 28,376 & 283,761 & 62.7 \\
\hline 1910-1919 & 3 & 0 & 3 & 1 & 1 & 0 & 543 & 5,433 & 1.2 \\
\hline 1920-1929 & 4 & 2 & 2 & 1 & 1 & 0 & 332 & 3,324 & 0.7 \\
\hline 1930-1939 & 5 & 2 & 3 & 3 & 2 & 1 & 1,727 & 17,274 & 3.8 \\
\hline 1940-1949 & 7 & 3 & 4 & 3 & 1 & 0 & 783 & 7,828 & 1.7 \\
\hline 1950-1959 & 10 & 5 & 5 & 2 & 2 & 0 & 518 & 5,178 & 1.1 \\
\hline 1960-1969 & 8 & 4 & 4 & 1 & 1 & 1 & 1,776 & 17,760 & 3.9 \\
\hline 1970-1979 & 9 & 7 & 2 & 1 & 1 & 0 & 758 & 7,582 & 1.7 \\
\hline 1980-1989 & 18 & 15 & 3 & 2 & 1 & 1 & 1,364 & 13,642 & 3.0 \\
\hline 1990-1999 & 8 & 5 & 3 & 1 & 1 & 1 & 8,790 & 87,905 & 19.4 \\
\hline 2000-2005 & 6 & 4 & 2 & 1 & 1 & 0 & 487 & 2,924 & 0.6 \\
\hline Total & 80 & 48 & 32 & 17 & 13 & 5 & 45,456 & 452,610 & 100 \\
\hline
\end{tabular}




\begin{tabular}{|c|c|c|c|c|}
\hline $\begin{array}{l}\text { Common } \\
\text { event name }\end{array}$ & Date & Location & $\begin{array}{c}\text { Estimated } \\
\text { property damage } \\
\text { (millions of event- } \\
\text { year dollars) }\end{array}$ & $\begin{array}{c}\text { Inflation- } \\
\text { adjusted damage } \\
\text { (millions of } 2005 \\
\text { dollars) }\end{array}$ \\
\hline Northridge & January 17, 1994 & Los Angeles metro area, Calif. & 38,700 & 46,983 \\
\hline San Francisco & April 18, 1906 & San Francisco Bay Area, Calif. & 524 & 8,942 \\
\hline Loma Prieta & October 18,1989 & San Francisco Bay Area, Calif. & 5,833 & 8,206 \\
\hline Good Friday & March 28, 1964 & Southern Alaska, Anchorage area & 780 & 2,736 \\
\hline Nisqually & February 28, 2001 & Seattle/Olympia areas, Wash. & 2,000 & 2,190 \\
\hline San Fernando Valley & February 9, 1971 & Los Angeles metro area, Calif. & 500 & 2,092 \\
\hline Whittier Narrows & October 1,1987 & Los Angeles metro area, Calif. & 350 & 542 \\
\hline Long Beach & March 11, 1933 & Los Angeles metro area, Calif. & 40 & 496 \\
\hline Olympia & April 13, 1949 & Olympia/Puget Sound, Wash. & 53 & 360 \\
\hline Bakersfield & July 21, 1952 & Bakersfield/Kern County, Calif. & 50 & 342 \\
\hline
\end{tabular}

in their effects, thus population corrections should account for the average change amongst all counties affected by each event. However, an earthquake occurring many decades ago may have caused considerable shaking but little damage in an area that at the time of the event was sparsely populated, but today is densely populated. The effect on the normalization in ignoring these areas would be a significant underestimate of the potential for contemporary damages.

To account for regional population changes, a "Combined Statistical Areas" approach is used to correct certain quakes. The combined statistical area (CSA) is a legal definition set by the Office of Management and Budget for use by the U.S. Census Bureau. The important CSAs used in the normalization adjustments are defined as:

- San Francisco Bay Area (SF CSA): Alameda, Contra Costa, Marin, San Francisco, San Mateo, and Santa Clara Counties.

- Los Angeles area (LA CSA): Kern, Los Angeles, Orange, Riverside, San Bernardino and Ventura Counties.

- Seattle area: King, Pierce, and Snohomish Counties.

The 1933 Long Beach (Calif.) earthquake (Tables 1 and 5) illustrates the approach of using a CSA rather than only the reported county. The Long Beach event caused extensive damage in Los Angeles County, but the earthquake also affected ten other Southern California counties (Stover and Coffman 1993), most of which were sparsely populated in 1933. While Los Angeles County has grown in population by a factor of 4 since 1933, other area counties have grown by as much as 15 times (San Bernardino County has grown from about 135,000 people in 1933 to almost 2 million people in 2005). The population adjustment factor between 1933 and 2005 using only Los Angeles County is 4.17; the adjustment factor using all counties in the Los Angeles metropolitan CSA is 6.36.

The CSA concept is informed by damage reports collated by Stover and Coffman (1993) and other sources. In general, the CSA adjustment factor is used to adjust any earthquake for which NGDC-i lists the maximum MMI as occurring in a county within a defined CSA. The use of a CSA is only an approximation of areas affected. Utilization of the CSA approach likely underestimates the potential for contemporary damages, as it excludes counties beyond the immediate metropolitan areas that are still potentially affected by shaking. Many of these counties have grown considerably in population and are in near-enough proximity to historic epicenters to expect damage in contemporary "repeat" quakes. The CSA usage therefore provides a conservative estimate of population increase for historic events.

The census unit used in the normalization calculations is indicated by a FIPS code (Federal Information Processing Standards), corresponding to an individual county (Appendix II). FIPS codes created for this paper and listed in Appendix II-corresponding to CSAs-are 6901 for the U.S. Census Bureau-defined SF CSA, 6902 for the LA CSA, and 53999 for the Seattle CSA. In some cases the defined CSA was not deemed appropriate; customized CSAs appearing in Appendix II for individual events are:

- 2099 for Anchorage Borough (FIPS =2020), Fairbanks North Star Borough (2090), and Valdez-Cordova Census Area (2261);

- 6903 for San Francisco County (6075) and Santa Clara County (6085);

- 6904 for Orange County (6059) and San Diego County (6073);

- 6905 for Los Angeles County (6037) and San Bernardino County (6071); and

- 30999 for Beaverhead County (30001) and Madison County (30057).

\section{Normalization Equation}

When the three adjustment factors are combined, the normalization calculation is performed as follows:

$$
D_{2005}=D_{y} \times I P D_{y} \times W_{y} \times \Delta P_{2005-y} \times\left[\mathrm{MF}_{y}\right]
$$

where $D_{2005}=$ normalized damages in 2005 dollars; $D_{y}=$ reported damages in event-year dollars; IPD $=$ inflation multiplier based on difference between year ( $y$ ) GDP and 2005 GDP; $W_{y}=$ wealth multiplier based on difference between FACDG in year (y) and FACDG in 2005; $\Delta P_{2005-y}=$ population change between 2005 and event year; and $\left[M F_{y}\right]=$ mitigation factor (either no mitigation [1], $1 \%$ mitigation [scaled percentage decrease from 2005], or $2 \%$ mitigation [scaled percentage decrease from 2005]; mitigation factors are described in the next section.

For example, using the consensus damage estimate (Appendix I), the 1964 Good Friday earthquake near Anchorage, Alaska would be normalized as 


$$
D_{2005}=\$ 540,000,000 \times 5.07 \times 2.44 \times 2.54=\$ 16,932,000,000
$$

where \$540 million is reported damages in 1964 dollars (consensus value), 5.07 is the inflation adjustment, 2.44 the wealth adjustment, and 2.54 the regional population correction factor accounting for the Anchorage Borough, Fairbanks North Star Borough, and Valdez-Cordova census areas. If the same calculation is performed with a $1 \%$ mitigation factor it proceeds as

$$
\begin{aligned}
D_{2005} & =\$ 540,000,000 \times 5.07 \times 2.44 \times 2.54 \times 0.66 \\
& =\$ 11,213,000,000
\end{aligned}
$$

\section{Accounting for Mitigation}

In the United States, considerable attention has been paid to structural mitigation of buildings in response to the threat of earthquakes. Such mitigation efforts will have the effect of decreasing normalized historical losses. Studies of the value of mitigation suggest a benefit to cost ratio of 2-4 (e.g. CBO 2007). Crompton and McAneney (in review) use a dummy variable to reflect an annual decrement in normalized losses resulting from tropical cyclone mitigation policies implemented in Australia. In addition to the no mitigation case, we consider two values for annual effects of mitigation, 1.0 and $2.0 \%$ reduction in structural vulnerability per year. A $1.0 \%$ reduction in vulnerability per year equates to a halving of vulnerability (and thus losses) over about 70 years, all else being equal, and a $2.0 \%$ reduction per year equates to a halving of vulnerability over about 37 years, all else being equal. It seems highly unlikely that earthquake mitigation has resulted in a decrease in vulnerability of more than $2.0 \%$ per year (e.g., suggesting that the same quake in the same location 74 years apart would result in $25 \%$ of the original losses, all else being equal). However, an evaluation of the effects of mitigation goes well beyond the scope of this paper, and we simply acknowledge that other values for the effectiveness of mitigation are plausible (both inside and outside of the range that we discuss). The values that we present are provided to illustrate the possible effects of mitigation over the long term on loss potentials.

For example, in the case of the 1964 Good Friday earthquake near Anchorage, Alaska, the $\$ 16.9$ billion normalized loss estimate is reduced to $\$ 11.2$ billion with $1 \%$ mitigation per year and $\$ 7.4$ billion with $2 \%$ mitigation. A consistent time series of disaster losses would also enable a more rigorous evaluation of the effectiveness of mitigation in comparison to growth in population and wealth. The results discussed below are presented with no mitigation, $1 \%$, and $2 \%$ mitigation.

\section{Inflation-Adjusted and Normalized Earthquake Losses}

The ten most damaging earthquakes adjusted only for inflation are listed in Table 5. All 17 events exceeding \$500 million in normalized damages by normalizing for inflation, wealth and population, and no mitigation, 1, and $2 \%$ mitigation are listed in Table 1. Figs. $3(\mathrm{a}-\mathrm{d})$ show annual time series of the inflation-adjusted case and the three mitigation cases with an eight-year running mean overlain on each. Figs. $4(\mathrm{a}-\mathrm{c})$ show the distributions of the no mitigation, 1 and $2 \%$ cases.
Normalization significantly readjusts the picture of damaging U.S. earthquakes. Whereas none of their inflation-adjusted damages exceeded \$500 million, events from 1918, 1933, 1949 in Puerto Rico, Los Angeles, and Olympia (Wash.), respectively adjust to between $\$ 800$ million and $\$ 16$ billion (Tables 1 and 5), indicating that these were extreme events. When only adjusting for inflation, the costliest earthquake in U.S. history is the 1994 Northridge event with losses near $\$ 50$ billion. With normalization, the 1906 San Francisco earthquake becomes the most costly, with losses of \$40-\$300 billion, depending upon mitigation, and with maximum losses exceeding $\$ 300$ billion when a larger affected area is considered (see 1906 San Francisco Earthquake section). With no mitigation, five events exceed $\$ 10$ billion in damages, thirteen exceed $\$ 1$ billion and seventeen exceed $\$ 500$ million. When $1 \%(2 \%)$ mitigation is considered, 14 (12) events exceed $\$ 500$ million, 11 (9) exceed $\$ 1$ billion and 4 (2) exceed $\$ 10$ billion. Fig. 5 shows the cumulative distribution function of losses for all three mitigation cases.

Earthquake magnitude and inflation-adjusted damage results are correlated at 0.12 . Using the normalized losses improves this correlation to 0.25 , suggesting that the normalization adds value to an inflation-only adjustment, as would be expected. Considering mitigation at $1 \%$ results in a correlation of 0.25 and $2 \%$ results in 0.20 . The difference in relationship with magnitude between no mitigation and $1 \%$ is not significant, but the degrading of the relationship at $2 \%$ is suggestive-but hardly conclusive-that mitigation may have an effect at less than $2 \%$. The overall low relationship should be expected given the uneven distribution of population and wealth in locations exposed to earthquakes, and the unique characteristics of different events. In other words, if population and wealth were uniformly distributed, and earthquake behavior was uniform for every event, we would expect a correlation between intensity and normalized damage of 1.0 .

In contrast to earthquakes, normalizing hurricanes to 2005 dollars, Pielke et al. (2008) found the most costly hurricane to be approximately $\$ 140$ billion from the 1926 Miami event. In 2005 dollars, 90 hurricanes exceed $\$ 1$ billion in damages and 27 exceed $\$ 10$ billion (Pielke et al. 2008), more than five times the number of earthquakes with no mitigation, and 6.8 and 13.5 times more with 1 and $2 \%$ mitigation, respectively.

Normalizing by wealth and inflation but not population, the most expensive tornado in U.S. history was the 1896 St. Louis event at \$2.9 billion in 1997 dollars (Brooks and Doswell 2001), or $\$ 4.2$ billion in 2005 dollars. When the Brooks and Doswell record is adjusted to 2005 dollars, only the 1896 tornado exceeds $\$ 2.5$ billion, 13 tornados exceed $\$ 1$ billion in damages, and an additional 11 adjust to between $\$ 500$ million and $\$ 1$ billion.

\section{Annual Normalized Losses}

Interpretation of annual losses from the data record is complicated by the temporal sparseness of events and damage data that is skewed to the recent decades of the 20th century [Fig. 1(a)]. Tables 2 and 3 list estimates made using various averaging windows and for different assumptions about mitigation. Sliding the averaging window is sensitive to the two extreme events (1906 and 1994 Northridge). If the 1906 San Francisco event is considered an outlier, annual losses increase when using more recent averaging periods. However, if both the 1906 event and the 1994 event are removed as outliers, no trend in annual losses is appar- 
Annual Inflation-Adjusted Earthquake Damage

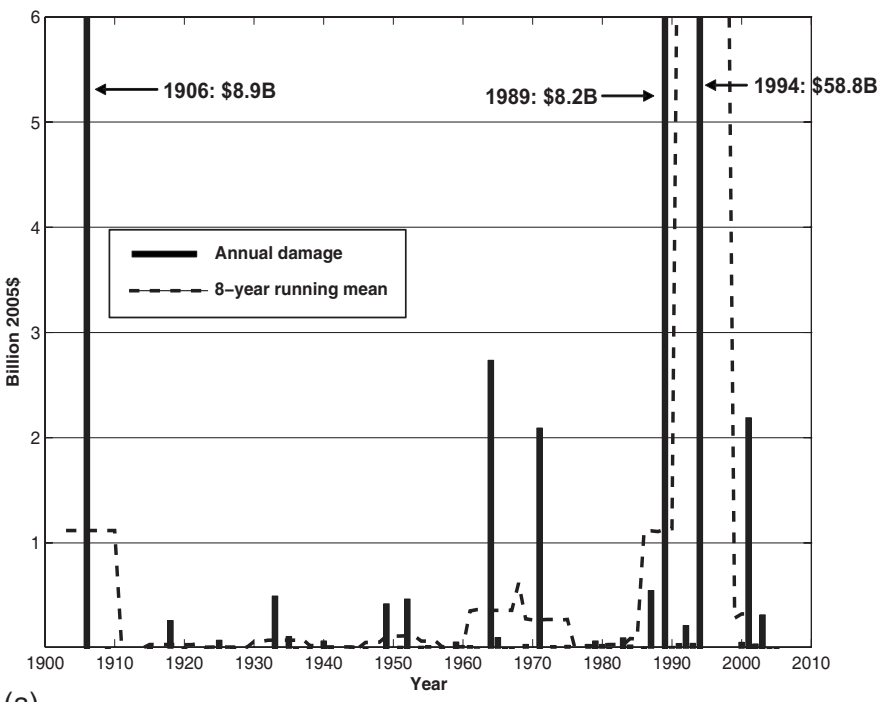

(a)

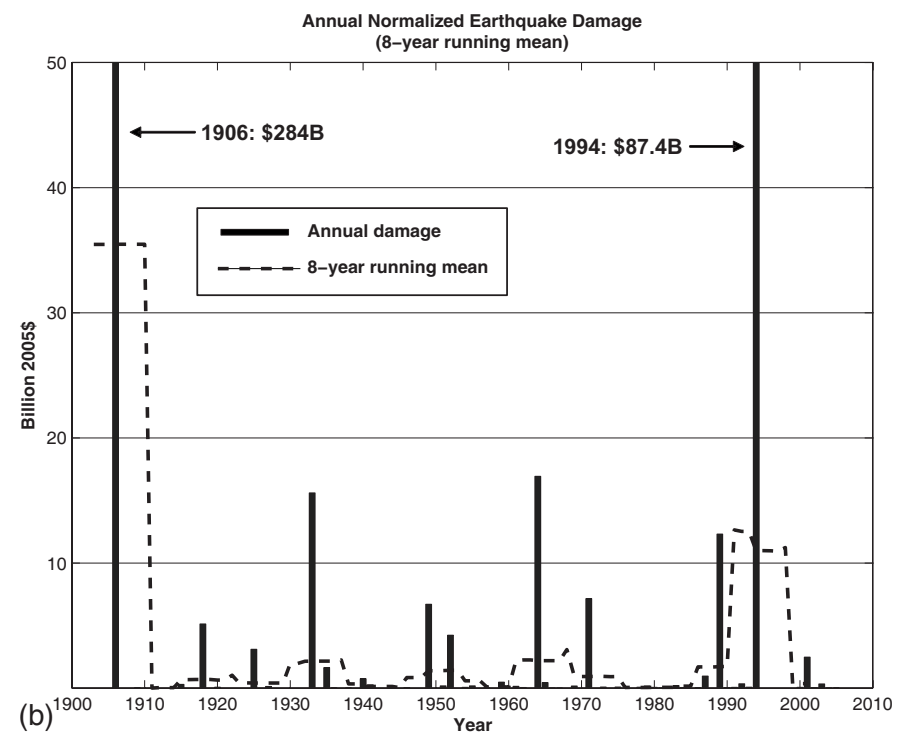

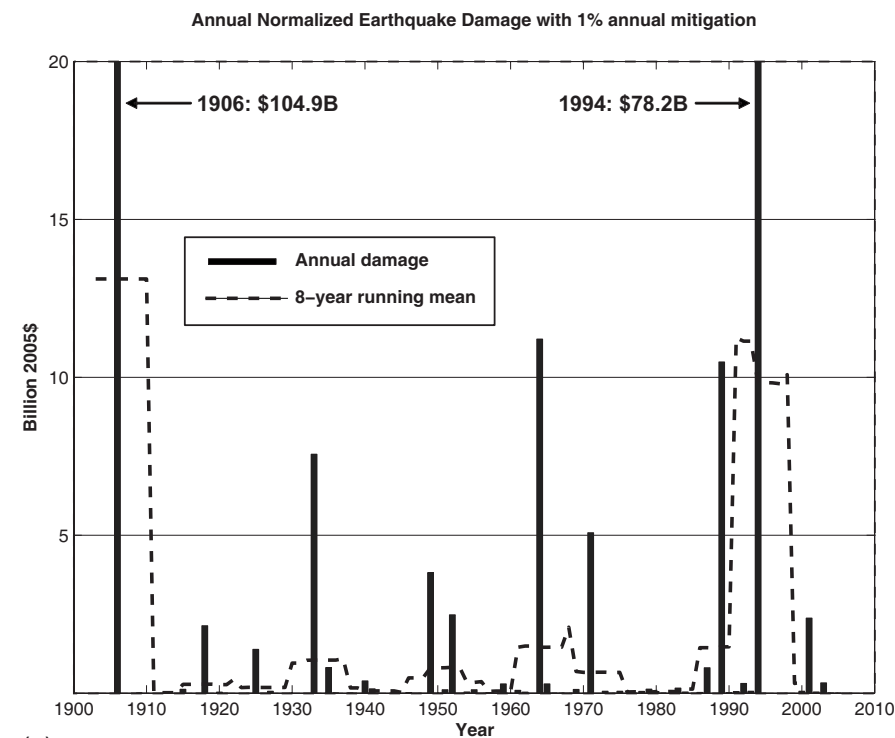

(c)

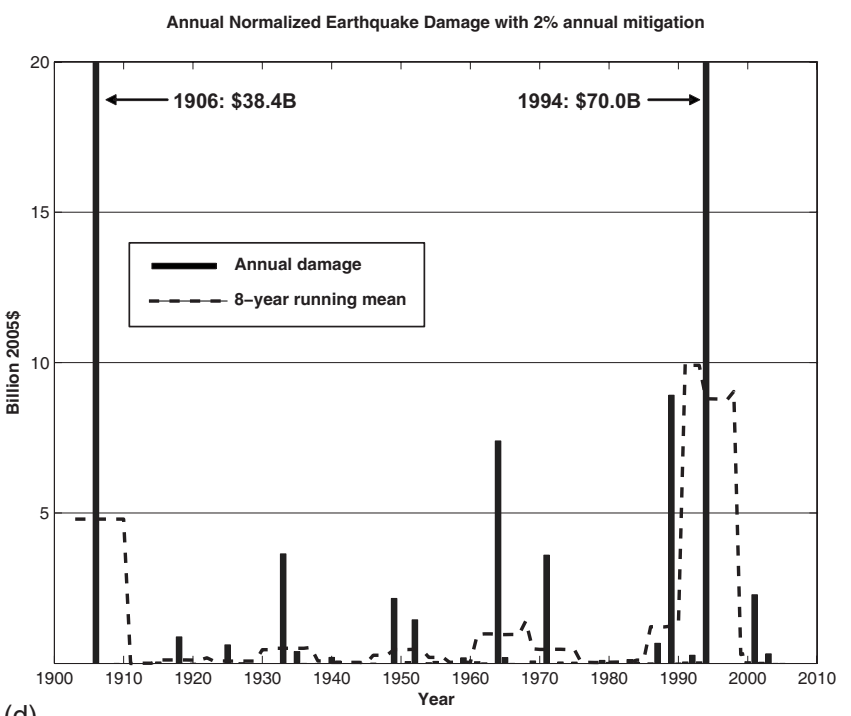

(d)

Fig. 3. Time series of annual earthquake losses for (a) inflation-adjusted case; (b) normalized case with no mitigation factor; (c) normalized with $1 \%$ annual mitigation factor; and (d) normalized with $2 \%$ annual mitigation factor. On each plot a 8 -year centered running mean is plotted (dashed line). As there is a five order of magnitude range in the data, not all events appear and some exceed the upper limit on the dependent axis (these events are labeled). Note that each plot is drawn with different y-axis increments and limits.

ent. Fig. 6 shows average annual losses by decade as a time series.

Estimates of annual losses using individual data sets (Dunbar et al. 2006; EM-DAT 2006; Hazards Research Lab 2006) rather than the consensus damage list produce a range of $\$ 434$ million to $\$ 4.7$ billion with a mean across data sets and averaging windows of $\$ 2.5$ billion ( $\$ 2.0$ billion and $\$ 1.7$ billion with 1 and $2 \%$ mitigation, respectively; Table 3 ).

Using earthquake damage simulations from the HAZUS catastrophe model, FEMA estimated in 2001 expected U.S. annual losses to be $\$ 4.4$ billion (in 1994 dollars; FEMA 2001). This loss estimate adjusts to $\$ 5.5$ billion accounting solely for inflation and $\$ 8.0$ billion in 2005 dollars accounting for inflation as well as proportional growth in national wealth and U.S. population with no adjustment for mitigation. With mitigation considered the FEMA annual estimate drops to about $\$ 7.2$ billion with $1 \%$ an- nual mitigation, and $\$ 6.4$ billion with $2 \%$ annual mitigation. A comparison with normalized losses developed here suggests that the normalized losses are considerably lower than those estimates provided by FEMA, especially when mitigation is considered in the normalization.

The discrepancy between HAZUS-derived estimates and estimates derived from the normalized record could result for several reasons. One explanation could be a low bias in historical loss estimates. A second could be consideration by HAZUS of large events for which there is no historical precedent, and thus not present in the normalized database. A third factor is macroeconomic factors that drive up the costs of losses (including "demand-surge") in the aftermath of an event (Pielke et al. 2008). In principle, normalized losses of accurate data spanning a range of events encompassing future possibilities should match well with estimates provided by catastrophe models. Because they do 


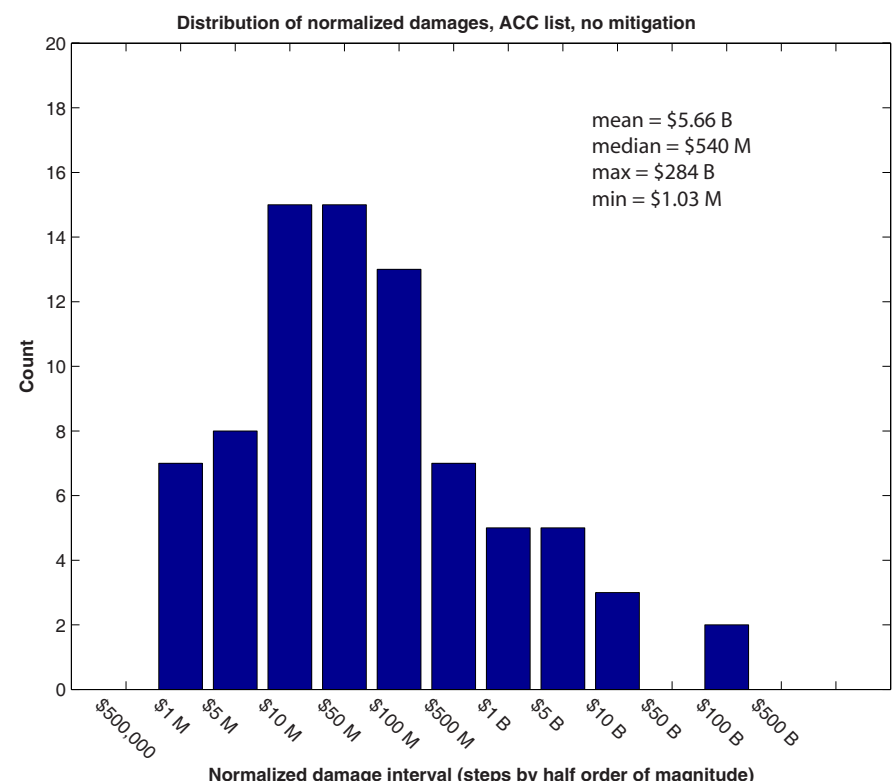

(a)

(\$2005 USD)

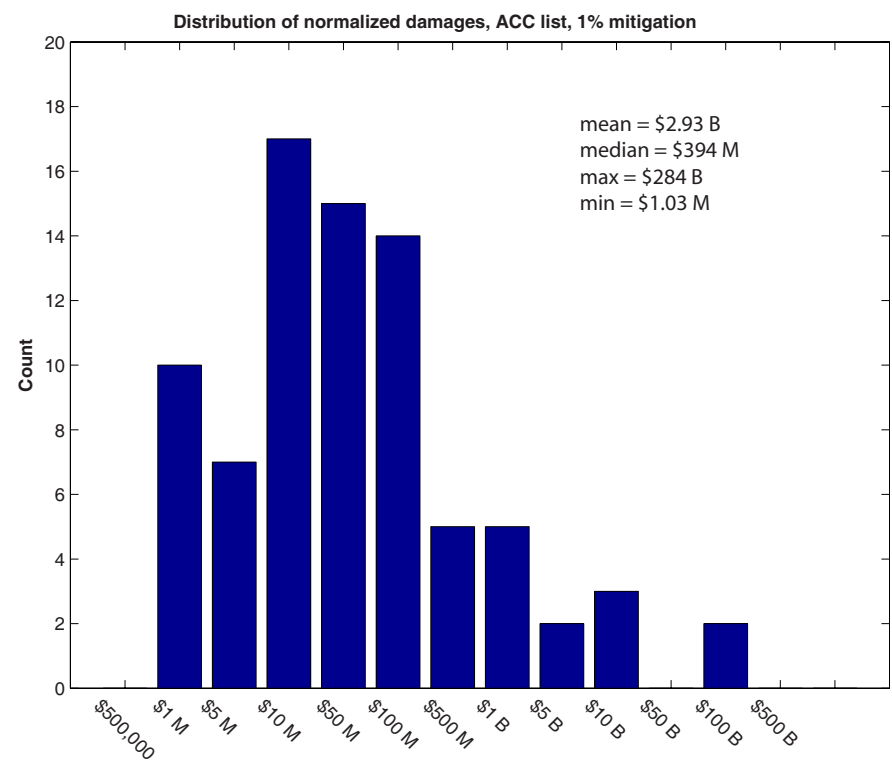

(b)

(\$2005 USD)

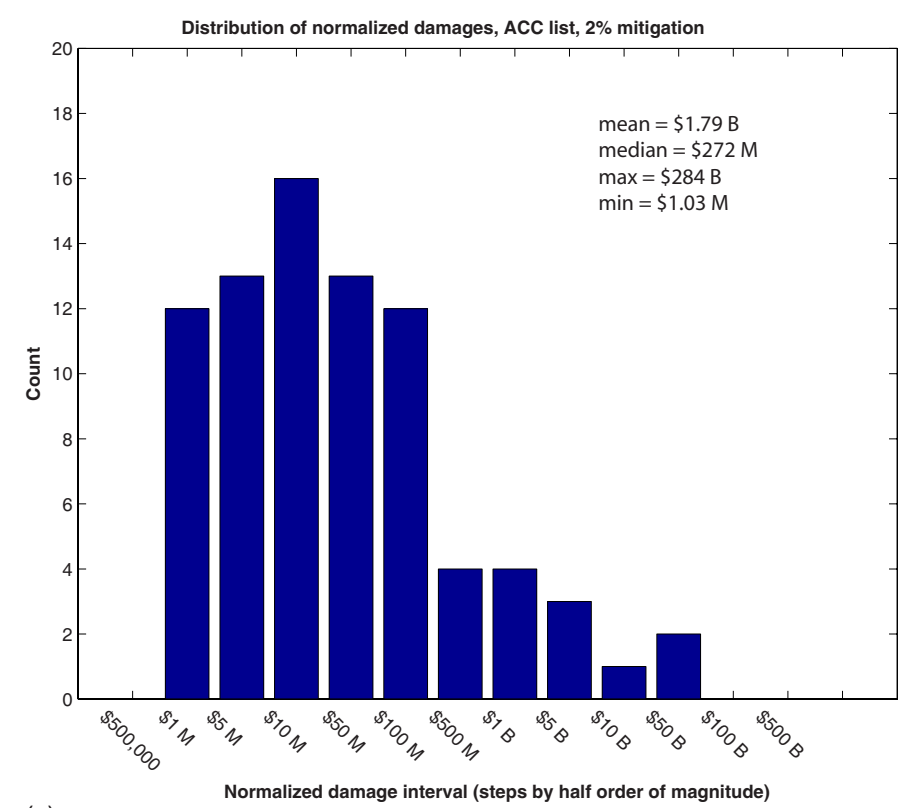

(c)

Fig. 4. Distribution of normalized damages for the (a) no mitigation; (b) $1 \%$ mitigation; and (c) $2 \%$ mitigation cases. Independent axis is log-scale and binning is set by half orders of magnitude.

not in this case should provide additional motivation to examine the reasons for the differences and improve the baseline information on observed earthquake losses, which goes beyond the scope of the present analysis.

\section{San Francisco Earthquake}

At $\$ 40$ billion- $\$ 328$ billion total loss, the April 18, 1906 San Francisco earthquake has the highest normalized loss (Tables 4 and 6). In 1906 dollars, damage estimates range from $\$ 350$ million (Haas et al. 1977) to $\$ 1$ billion (Steinbrugge 1982). The $\$ 350$ million estimate only counts the cost to rebuild the city of San Francisco, so should be considered a lower bound on total loss.
Some groups cite a $\$ 400$ million estimate (Algermissen et al. 1972; Steinbrugge 1982), but currently the most accepted value, considered here as the best estimate, is \$524 million (Munich Re 2001; Dunbar et al. 2006; EM-DAT 2006; Munich Re 2006). Munich Re (2006) implies that the $\$ 524$ million is conservative.

Different population corrections for the 1906 event can be justified. The event produced greatest damage in San Francisco County, which was the county both closest to the epicenter and the most densely populated during the event. However, many other areas far afield were severely damaged, most notably the city of Santa Rosa in Sonoma County (outside of the SF CSA). The Lawson Report (Lawson 1908) identifies eighteen counties damaged by shaking. Adjusting for San Francisco County alone is considered a lower bound. The SF CSA is used for consistency 


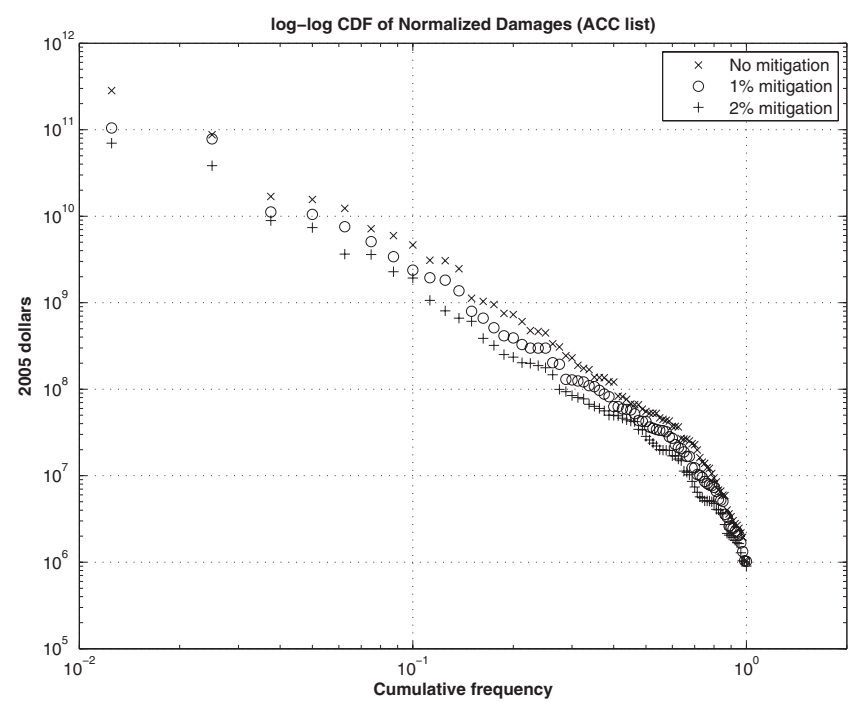

Fig. 5. Log-log cumulative distribution function (CDF) of normalized losses for the no mitigation (circles; upper-most trend), $1 \%$ mitigation ( $\times$ 's; middle trend), and $2 \%$ mitigation (crosses; bottom-most trend) cases

with how other events are treated in this analysis. The 18-county correction factor, considered most realistic, gives the highest population multiplier at 9.28 , about $15 \%$ greater than the SF CSA correction (Table 6).

Utilizing various 1906-value loss estimates and population factors, the normalization adjustments range from $\$ 45$ billion to $\$ 626$ billion, with $\$ 328$ billion the result of using the $\$ 524$ million estimate and the 18-county population correction factor. The SF CSA population factor adjusts to $\$ 284$ billion. When the $1 \%$ ( $2 \%$ ) mitigation factor is used with the $\$ 524$ million damage estimate and the 18-county population factor, the normalized damage adjusts to $\$ 121$ billion ( $\$ 44$ billion); when mitigation is used

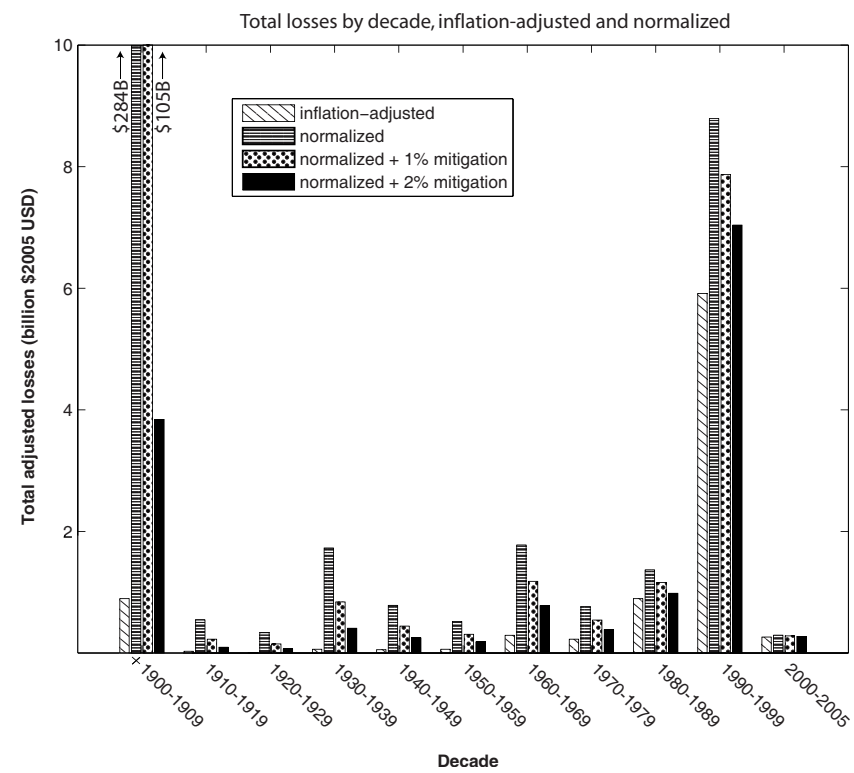

Fig. 6. Total losses by decade for the inflation-adjusted (crosshatched), normalized with no mitigation (horizontal hatching), normalized with $1 \%$ mitigation (dotted) and $2 \%$ mitigation (solid) cases with the CSA population factor the adjusted values are \$105 billion ( $\$ 38$ billion).

Using a total damage estimate of $\$ 350$ million-\$500 million, Odell and Weidenmier (2004) cite the 1906 event as costing 1.3$1.8 \%$ of nominal 1906 U.S. GNP. As a percentage of 2005 U.S. GNP ( $\$ 12,521$ billion), $1.3-1.8 \%$ is $\$ 163$ billion- $\$ 225$ billion, comparable to the normalized adjustment. The discrepancy can be explained by the differences in population increase between the San Francisco area and the United States as a whole: since 1906 U.S. population has increased by about 3.5 times whereas the San Francisco area population has increased 8-9 times.

\section{Adjusted Earthquake Fatalities}

Earthquake event fatalities can be adjusted similarly to the damage adjustment, providing a relative comparison in noneconomic terms of the magnitude of various calamities, a method pursued for Caribbean hurricanes by Pielke et al. (2003). Fatalities are adjusted only using population change, not economic metrics. As for the damage normalization, the intent is not to estimate how many people would perish in the same earthquake today, but rather to estimate how many people would have perished in the event had it occurred with today's population, all else being equal. As with economic losses, mitigation can also be considered as a factor that serves to reduce losses. The calculation proceeds exactly as for the damage normalization while leaving out the wealth and inflation multipliers

$$
F_{2005}=F_{y} \times \Delta P_{2005-y} \times\left[M F_{y}\right]
$$

where $F_{2005}=$ adjusted fatalities; and $F_{y}=$ event fatalities. The Alaska Good Friday adjustment with $1 \%$ mitigation proceeds as

$$
F_{2005}=131 \times 2.54 \times 0.66=220
$$

Fatalities that have been recorded for 31 U.S. earthquakes are multiplied by the change in local population from the year of the event to 2005 (Table 7). Some records conflict in fatality numbers for a given event; in those cases the range is presented. All fatality estimates use the numbers given by the data sets employed for this paper, except for the 1906 event. Because the 1906 San Francisco event was a defining moment for the region and country, considerable research has been undertaken on the event. While all database records give a fatalities estimate of 700 (Algermissen et al. 1972) or 2,000 (original source unknown) for this event, more recent research by Hansen and Condon (1989) indicates that fatalities were over 3,000, a number now used by the USGS, Munich Re (2006), and other groups.

When adjusted for population increase and no mitigation, six events caused over 100 fatalities and the 1906 event adjusts to over 24,000 fatalities (Table 7). The second most deadly event is the 1933 Long Beach (Los Angeles area) earthquake with about 700 fatalities. An M7.9 event occurring near San Francisco today-similar to the 1906 event-is expected to cause an estimated 800-3,400 fatalities depending upon the time of day of shaking (Kircher et al. 2006a). With mitigation of $1 \%$ and $2 \%$ per year the 1906 quake adjusts to 8,900 and 3,250 deaths, respectively. The difference between the values presented here with mitigation and Kircher et al. (2006a), when compared to the normalized economic losses suggest a hypothesis that U.S. (and California) earthquake policy has been more successful in its focus on reducing loss of human life than economic damage. This is certainly the situation with respect to hurricanes, where loss of 
Table 6. Estimates for Normalization of April 18, 1906 San Francisco Earthquake by Population Correction Factor and Original Damage Estimate (Millions of 2005 Dollars)

\begin{tabular}{|c|c|c|c|c|}
\hline & & \multicolumn{3}{|c|}{ Normalized damage (millions of 2005 dollars) } \\
\hline & & $\begin{array}{c}\text { San Francisco } \\
\text { County }\end{array}$ & SFBA CSA & $\begin{array}{c}\text { All } 18 \\
\text { counties }\end{array}$ \\
\hline & $\begin{array}{c}\text { Population } \\
\text { multiplier }\end{array}$ & 1.91 & 8.02 & 9.28 \\
\hline \multirow{13}{*}{$\begin{array}{l}\text { No mitigation } \\
\text { ( } 1 \% \text { mitigation) } \\
(2 \% \text { mitigation) }\end{array}$} & $\begin{array}{l}\text { Loss estimate } \\
\text { (million } 1906 \$)\end{array}$ & & & \\
\hline & 1,000 & $\$ 128,904$ & $\$ 541,480$ & $\$ 626,218$ \\
\hline & & $(\$ 47,660)$ & $(\$ 200,201)$ & $(\$ 231,531)$ \\
\hline & & $(\$ 17,444)$ & $(\$ 73,276)$ & $(\$ 84,744)$ \\
\hline & 524 & $\$ 67,546$ & $\$ 283,735$ & $\$ 328,138$ \\
\hline & & $(\$ 24,974)$ & $(\$ 104,905)$ & $(\$ 121,322)$ \\
\hline & & $(\$ 9,141)$ & $(\$ 38,397)$ & $(\$ 44,406)$ \\
\hline & 400 & $\$ 51,562$ & $\$ 216,592$ & $\$ 250,487$ \\
\hline & & $(\$ 19,064)$ & $(\$ 80,080)$ & $(\$ 92,613)$ \\
\hline & & $(\$ 6,978)$ & $(\$ 29,311)$ & $(\$ 33,897)$ \\
\hline & 350 & $\$ 45,116$ & $\$ 189,518$ & $\$ 219,176$ \\
\hline & & $(\$ 16,681)$ & $(\$ 70,070)$ & $(\$ 81,036)$ \\
\hline & & $(\$ 6,105)$ & $(\$ 25,647)$ & $(\$ 29,660)$ \\
\hline
\end{tabular}

life has been reduced dramatically (with the notable exception of Hurricane Katrina) while economic losses have escalated dramatically (and remained unchanged after normalization).

\section{Discussion/Conclusion}

The most damaging hurricane in U.S. history, the 1924 Miami event, normalizes to $\$ 137$ billion in normalized 2005 dollars (Bouwer et al. 2007) and the most expensive tornado, the 1896 St. Louis event, normalizes to $\$ 4.2$ billion (2005 dollars, not adjusted for population, Brooks and Doswell 2001). With the possible exception of the 1930's Dust Bowl (Hansen and Libecap 2004), the 1906 San Francisco arguably normalizes to the most expensive single natural disaster event in U.S. history since 1900, although there is some remaining uncertainty. Consistent with the findings of this analysis, the 1906 event represented the single greatest event loss in the 125-year history of the Munich Re Reinsurance Company (Munich Re 2006).

A majority of high-fatality events occurred prior to the era of modern building codes, but after all events are adjusted, recent California quakes of 1971 (San Fernando), 1989 (Loma Prieta) and 1994 (Northridge) are the 6th, 9th, and 10th most deadly events. This suggests that while technological sophistication may be a factor in reducing fatalities relative to population levels $(10$ of the 13 events with more than 30 adjusted fatalities occurred before 1965), loss potential remains a concern for modern earthquakes.

Earthquakes fall between hurricanes and tornados in terms of frequency of extreme damages. In 2005 dollars, 90 hurricanes exceed $\$ 1$ billion in damages and 27 exceed $\$ 10$ billion, more than five times the number of earthquakes with commensurate damages. Only 13 tornados exceed $\$ 1$ billion in damages and only one tornado exceeds \$3 billion (Brooks and Doswell 2001). However, while hurricanes are far more frequent than large earth- quakes with aggregated losses more than double that of earthquakes ( $\$ 1.05$ trillion versus $\$ 432$ billion), at the highest level, damages are similar, especially when mitigation is considered in earthquake damage.

The loss data are suggestive of an imbalance between actual damage created by various hazard types and U.S. research and development (R \& D) spending on hazards. While weatherrelated hazards produce two to three times the damages of earthquakes, federal spending on weather-related hazards are more than an order of magnitude higher than spending on earthquakes (Meade and Abbott 2003). Drawing from Pielke and Carbone (2002), Meade and Abbott account for floods, hurricanes, winter storms, tornadoes, hail, extreme heat, and extreme cold in their weather-related losses calculation; they consider only federal funding in their spending analysis. The results of this paper suggest that the actual damage gap may be even greater than that noted by Meade and Abbott (4.3 times greater weather-related losses than earthquake losses), but still not at a level of equity with funding differences. Looking forward, an important question in natural hazards policy is whether or how to reconcile hazards R\&D spending with damages, and more importantly, preventable damages resulting from $R \& D$ investments.

An important implication of this analysis is that it provides real-world loss data with which to compare catastrophe model outputs. For example, using a HAZUS model analysis with estimated 1906 ground motions over the 19-county northern California/San Francisco area, a modern repeat of the April 1906 shaking is expected to produce $\$ 90$ billion- $\$ 120$ billion in property loss to buildings (Kircher et al. 2006a). A comparison of HAZUS-derived losses to actual losses of the 1994 Northridge earthquake found that HAZUS produced "modestly conservative" estimates of damage and loss (Kircher et al. 2006b). The $\sim \$ 40$ billion $-\$ 300$ billion results from normalization imply 
Table 7. Earthquake Fatalities Adjusted for Population Increase

\begin{tabular}{|c|c|c|c|c|c|c|}
\hline $\begin{array}{l}\text { Event } \\
\text { date }\end{array}$ & Location & $\begin{array}{l}\text { Event } \\
\text { deaths }\end{array}$ & $\begin{array}{c}\% \text { of total } \\
\text { population } \\
(\%)\end{array}$ & $\begin{array}{c}\text { Proportional } \\
\text { deaths } \\
\text { (no mitigation) }\end{array}$ & $\begin{array}{c}1 \% \\
\text { mitigation }\end{array}$ & $\begin{array}{c}2 \% \\
\text { mitigation }\end{array}$ \\
\hline $4 / 18 / 1906$ & San Francisco, Calif. & 3,000 & 0.4112 & 24,062 & 8,896 & 3,256 \\
\hline $6 / 22 / 1915$ & El Centro, Calif. & 6 & 0.0210 & 33 & 13 & 5 \\
\hline 10/11/1918 & Mona Passage, Puerto Rico & 116 & 0.0082 & 331 & 138 & 57 \\
\hline $6 / 29 / 1925$ & Santa Barbara, Calif. & 13 & 0.0245 & 98 & 44 & 19 \\
\hline 3/11/1933 & Long Beach, Calif. & $100-116$ & 0.0035 & $636-737$ & $308-357$ & $149-172$ \\
\hline $10 / 19 / 1935$ & Helena, Mont. & $2-4$ & 0.0099 & $6-12$ & $3-6$ & 1 \\
\hline 10/31/1935 & Helena, Mont. & 2 & 0.0099 & 6 & 3 & 1 \\
\hline $5 / 19 / 1940$ & El Centro/Imperial Valley, Calif. & $8-9$ & 0.0151 & $21-23$ & $11-12$ & 6 \\
\hline 4/13/1949 & Olympia, Wash. & 8 & 0.0181 & 41 & 24 & 13 \\
\hline $7 / 21 / 1952$ & Kern county/Bakersfield, Calif. & $12-14$ & 0.0054 & $38-44$ & $22-26$ & $13-15$ \\
\hline $8 / 22 / 1952$ & Kern county/Bakersfield, Calif. & 2 & 0.0008 & 6 & 4 & 2 \\
\hline $12 / 21 / 1954$ & Eureka-Arcata, Calif. & 1 & 0.0012 & 2 & 1 & 1 \\
\hline $10 / 24 / 1955$ & Concord-Walnut Creek, Calif. & 1 & 0.0003 & 3 & 2 & 1 \\
\hline $3 / 22 / / 1957$ & Daly City, Calif. & 1 & 0.0003 & 2 & 1 & 1 \\
\hline $8 / 18 / 1959$ & Hebgen Lake, Mont. & 28 & 0.1092 & 85 & 54 & 34 \\
\hline $3 / 28 / 1964$ & Anchorage/Fairbanks, Alaska & 131 & 0.0892 & 332 & 220 & 145 \\
\hline $4 / 29 / 1965$ & Seattle, Wash. & 7 & 0.0005 & 13 & 9 & 6 \\
\hline $10 / 2 / 1969$ & Santa Rosa, Calif. & 1 & 0.0005 & 2 & 2 & 1 \\
\hline 2/9/1971 & San Fernando, Calif. & $58-65$ & 0.0006 & $102-114$ & $72-81$ & $51-57$ \\
\hline $11 / 29 / 1975$ & Kalapana (Kilauea), Hawaii & 2 & 0.0026 & 4 & 3 & 2 \\
\hline $1 / 24 / 1980$ & Livermore, Calif. & 1 & 0.0000 & 1 & 1 & 1 \\
\hline $11 / 8 / 1980$ & Northwestern Calif. & 5 & 0.0046 & 6 & 5 & 4 \\
\hline $10 / 28 / 1983$ & Borah Peak, Id. & $2-3$ & 0.0831 & $2-3$ & 2 & $1-2$ \\
\hline 10/1/1987 & Whittier (Los Angeles), Calif. & 8 & 0.0001 & 10 & 9 & 7 \\
\hline 10/18/1989 & Loma Prieta (SF Bay Area), Calif. & 62 & 0.0012 & 71 & 60 & 51 \\
\hline 6/28/1991 & Pasadena area, Calif. & 2 & 0.0000 & 2 & 2 & 2 \\
\hline $6 / 28 / 1992$ & Landers, Calif. & $1-3$ & 0.0002 & $1-4$ & $1-3$ & $1-3$ \\
\hline $9 / 21 / 1993$ & Klamath Falls, Ore. & 2 & 0.0034 & 2 & 2 & 2 \\
\hline $1 / 17 / 1994$ & Northridge, Calif. & 60 & 0.0004 & 69 & 62 & 56 \\
\hline 2/28/2001 & Seattle area, Wash. & 1 & 0.0000 & 1 & 1 & 1 \\
\hline $12 / 22 / 2003$ & San Robles, Calif. & 2 & 0.0008 & 2 & 2 & 2 \\
\hline
\end{tabular}

the possibility of larger or smaller losses than suggested by HAZUS. Munich Re (2006) notes that other estimates of economic losses of a repeat of the 1906 event run as high as $\$ 400$ billion, a figure well in line with the range of normalizations produced in this analysis.

In addition to estimating a range of economic losses from a 1906 repeat, the Kircher et al. (2006a) study also estimates expected fatalities at $800-3,400$, similar to the adjusted fatalities derived in this paper using a $2 \%$ mitigation factor $(3,250)$ and far lower than the fatalities derived from simple population scaling with no mitigation $(24,000)$. The difference in expected fatalities from those resulting from a simple scaling implies strong success in reducing fatality risk exposure, whether through governmentdirected mitigation programs or natural evolution of building technology.

This analysis should be considered only a first-step toward establishing a rigorous approach to normalized earthquake losses in the United States. Most important for improved estimates is the establishment of a high quality time series of earthquake losses. However, considering the widely varying loss estimates from major recent earthquakes such as the 1994 Northridge and 2001 Nisqually (Seattle) events, it is difficult to have confidence in the accuracy of reported disaster losses through time. Compilation of loss estimates for this analysis bolster the observations of NRC (1999) and Meade and Abbott (2003) that a lack of standardization of disaster loss data collection hampers the ability to assess disaster losses, as well as the effectiveness of disaster mitigation policies. Detailed, systematic research into past event losses and a reconciliation of methods for future loss data collection with past loss estimates, combined with the methods of this paper, would add value to the decision-making process on hazards research and development.

\section{Acknowledgments}

We thank Joel Gratz for sharing processed BEA wealth data. During the term of this research, Kevin Vranes was supported by a Visiting Fellowship of the Cooperative Institute for Research in the Environmental Sciences, University of Colorado.

\section{Appendix I. Loss Estimates}

In many of the 80 earthquake events cited in this paper, multiple sources for an event give conflicting damage estimates. The fol- 
lowing is a brief discussion of those events with a discussion of the number used in this paper for the "middle" or "ACC" list. All available estimates are listed in Appendix II.

As a general rule, the most conservative estimate was used by Pielke and Landsea (1998) for hurricanes. However, in the case of earthquake losses, sometimes the most conservative estimate is clearly an outlier when all sources are taken into consideration. In all cases where discrepancies exist, an attempt is first made to find a consensus number. If a consensus does not clearly emerge, a judgment is made on whether one number or range of numbers is more credible than another. Finally, if no consensus or credible numbers emerge, an average of the high and low numbers is used.

- San Francisco (Calif.), April 18, 1906. Sources range between $\$ 24$ million (Coffman et al. 1982) and $\$ 80$ million to $\$ 400$ million (Algermissen et al. 1972; Dunbar et al. 2006) to $\$ 1$ billion (Steinbrugge 1982), but the majority of sources list this event as costing $\$ 524$ million, which is the figure used here. It should be noted that \$524 million includes the fire and dynamiting of buildings for firefighting, but only counts building loss in the city of San Francisco (Munich Re. 2006). Coffman et al. (1982) estimated that actual shaking produced only $\$ 24$ million in damages, but it is impossible to differentiate between buildings that were only destroyed because of fire and would have otherwise been in acceptable condition in the absence of the fire. Munich Re (2006) states that the \$524 million estimate is conservative.

- Santa Barbara (Calif.), June 29, 1925. NGDC-s gives estimates of $\$ 8$ million and $\$ 6$ million but only $\$ 8$ million is supported in the literature cited. EM-DAT uses the $\$ 8$ million estimate.

- Helena (Mont.), October 1935. There were over 1000 felt earthquakes in a swarm between October 12, 1935 and February 1936, but the October 19 and 31 events caused the most damage. Loss estimates vary widely, from a minimum of $\$ 3$ million Stover and Coffman (1993) (hereafter referred to as "SC1527" using the USGS file report number) to a maximum of $\$ 19$ million (EM-DAT) for the October 19 event. There is some confusion in the literature as to whether losses cited were for the aggregate of the October 19 and October 31 events, or whether losses for each were cited separately. Stover and Coffman (1993) cite \$3 million for the October 19 event but newspaper sources indicate that the number was probably higher. The $\$ 19$ million figure is plausible given the damage descriptions but is not supported in a scan of newspaper articles. Newspaper articles on the events were collected by the University of Utah Seismograph Stations (http://www.seis. utah.edu/lqthreat/nehrp_htm/1935hele/1935he1.shtml). For the ACC list, the $\$ 3.5$ million estimate in NGDC-s is used for the October 19 event and $\$ 6$ million is used for the October 31 event. It is possible that $\$ 6$ million estimate for the October 31 event is an estimate of total damage from both events, but it is the only number available. The $\$ 3.5$ million number is probably conservative while the $\$ 6$ million figure is likely an overestimate of single-event damages from the October 31 event.

- El Centro (Calif.), May 19, 1940. Two estimates are cited in various sources: $\$ 6$ million and $\$ 33$ million. The $\$ 6$ million figure appears to refer to damage in Imperial Valley, El Centro and Holtsville while the $\$ 33$ million figure encompasses damage that also occurred around Mexicali in Mexico. Some sources cite damage to irrigation systems that led to crop failures but no additional loss estimates are given. The \$6 million figure is used for the ACC list and is probably conservative.
- Massena (N.Y.), September 5, 1944. The database sources used cite estimate of $\$ 1.5$ million and $\$ 2.0$ million but at least one source cites damages of $\$ 18$ million. The event occurred on the New York-Ontario border and also affected Cornwall, Ontario. It is not clear if damages have been differentiated between Massena and Cornwall in any of the estimates. (Hodgson 1945) estimates Massena damage at \$1 million and Cornwall damage at $\$ 1$ million while noting that damage seemed more severe in Cornwall. An average of the $\$ 1.5$ million and \$2.0 million estimates are used for the ACC list.

- Olympia/Puget Sound (Wash.), April 13, 1949. The range of estimates is \$25 million to \$80 million and an average of those is used for the ACC list. Like many other events, the difference in estimates is between $\mathrm{SC} 1527$ on the low side and EM-DAT on the high side. (Noson et al. 1988) give a figure of $\$ 150$ million in 1984 dollars, which adjusts to approximately $\$ 36$ million in 1949 dollars. One USGS page claims the event caused over $\$ 250$ million in damages.

- Bakersfield/Kern County (Calif.), July 21, 1952. Damage estimates range from $\$ 50$ million to $\$ 60$ million and an average of the two figures is used here. This is one of the few events for which EM-DAT is on the low side of the estimates.

- Bakersfield/Kern County (Calif.), August 22, 1952. This event was the second largest of the July-August swarm. Stover and Coffman (1993) list \$10 million in damages while EMDAT gives a $\$ 30$ million estimate. The average of the high and low estimates (\$20 million) is used here.

- Hebgen Lake (Mont.), August 18, 1959. The largest earthquake in Montana history. All sources except for EM-DAT estimate losses at $\$ 11$ million and no accounts can be founding supporting EM-DAT's estimate of \$26 million, so \$11 million is used.

- Cache Valley (Utah), August 30, 1962. SC1527 cite \$1 million in losses while NGDC-s cites $\$ 2$ million based on an UNESCO source. An average of the two is used.

- Good Friday (Alaska), March 28, 1964. EM-DAT gives an estimate of $\$ 1.02$ billion while NGDC-s gives an estimate of $\$ 540$ million. The lower estimate is much better supported, so it used here.

- Seattle-Tacoma (Wash.), April 29, 1965. Two values are given in the databases: $\$ 12.5$ million (SC1527) and \$28 million (EM-DAT). (Noson et al. 1988) give damages of $\$ 50$ million in 1984 dollars, adjusting to $\$ 16.7$ million in 1965 dollars. An average of the \$12.5 million and \$28 million figures is used.

- Santa Rosa/Sonoma County (Calif.), October 2, 1969. Estimates range from $\$ 7$ million to $\$ 10$ million. An average of three estimates is used (\$8.45 million).

- San Fernando (Calif.), February 9, 1971. All damage estimates for this event are within a few percent, from \$500 million to $\$ 570$ million. The CAGS estimate is $\$ 505$ million, EM-DAT is $\$ 535$ million and NGDC-s lists sources between $\$ 500$ million to $\$ 553$ million. The 1999 Economic Report of the President (Office of the President 1999) gives a value of $\$ 1.7$ billion in 1992 dollars, which adjusts to $\$ 570$ million in 1971 dollars. An average of all estimates (\$539.5 million) is used.

- Kilauea, Hawaii (Hawaii), April 26, 1973. Estimates differ slightly (\$5.6 million versus $\$ 5.75$ million); an average is used. 
- Oroville Reservoir (Calif.), August 1, 1975. SC1527 cite $\$ 2.5$ million in damages but other sources cite \$6 million. No other information could be found on the event. An average of the two values is used.

- Goleta (Calif.), August 13, 1978. Estimates range from a low of $\$ 1.5$ million to a high of $\$ 15$ million. (Miller 1979) cites an estimate of "more than $\$ 7$ million." The City of Santa Barbara General Plan, dated August 1979, cites total damages of $\$ 11.62$ million. Other sources give ranges from \$12 million-\$15 million. As the University of California-Santa Barbara campus alone reported damages over $\$ 3$ million, the $\$ 1.5$ million estimate is clearly incorrect. The $\$ 15$ million estimate seems most plausible considering all sources, so it is used.

- Imperial Valley (Calif.), October 15, 1979. Two estimates differ by an order of magnitude (\$3 million versus \$30 million) but the higher number appears to be better supported and is used by the California Geological Survey.

- Livermore (Calif.), January 24, 1980. Estimates of \$3.5 million and $\$ 11.5$ million are available but the higher number appears better supported. The lower number is improbable as at least \$10 million in damage was reported at the Lawrence Livermore National Laboratory.

- Borah Peak (Id.), October 28, 1983. Estimates range from $\$ 12.5$ million-\$15 million-\$25 million. An average of the highest and lowest estimates (\$18.75 million) is used.

- Kapapala, Hawaii (Hiwaii), November 16, 1983. Estimates vary slightly from $\$ 6.25$ million- $\$ 6.5$ million; the average is used.

- Morgan Hill/Santa Clara (Calif.), April 24, 1984. Estimates range from $\$ 7.5$ million-\$30 million with $\$ 8$ million and $\$ 10$ million also given. An average of the highest and lowest estimates is used (\$18.75 million).

- Palm Springs (Calif.), July 8, 1986. Two estimates are available, $\$ 4.5$ million and $\$ 6$ million. An average of the two is used.

- San Diego/Newport Beach (Calif.), July 13, 1986. An average of two available estimates $(\$ 720,000$ and $\$ 1$ million) is used.

- Chalfant Valley/Bishop (Calif.), July 13, 1986. Estimates of $\$ 1$ million (NGDC) and \$2.7 million (SC1527) are cited and an average is used.

- Whittier/Los Angeles (Calif.), October 1, 1987. Estimates range from \$213 million (EM-DAT) to \$358 million (NGDC based on SC1527). Two other records in NGDC cite $\$ 350$ million, so the lower estimate is discarded and an average of the two higher estimates is used (\$354 million).

- Loma Prieta (Calif.), October 18, 1989. NGDC-s lists an estimate of $\$ 12$ billion, but lists its source as EM-DAT. However, EM-DAT currently estimates $\$ 5.6$ billion in damages and SHELDUS estimates $\$ 5.9$ billion. The California Geological Survey and Munich Re list estimates of $\$ 6$ billion in damages, which may simply be a rounding of either of the $\$ 5.6$ billion or $\$ 5.9$ billion estimates. Table 2.2 of the 1999 Economic Report of the President cites an estimate of $\$ 14.4$ billion (adjusted to 1989 dollars, Office of the President 1999, p. 82). Since this seems to be an outlier from a group of similar reports, an average of the three lower estimates, or $\$ 5.8$ billion, is used.
- Ferndale/Petrolia/Humboldt County (Calif.), April 25, 1992. Estimates range from $\$ 66$ million (NGDC and SHELDUS) to $\$ 75$ million (EM-DAT) to $\$ 100$ million (NGDC), although the highest estimate references EM-DAT as its source. CAGS estimates damages at $\$ 48.3$ million. A California State University-Humboldt $(\mathrm{CSUH})$ web page cites $\$ 60$ million. Most news reports in the two months following the event give a number of $\$ 51$ million but some cite $\$ 61$ million. $\$ 66$ million is used as the best consensus figure.

- Landers (Calif.), June 28, 1992. Most sources cite a figure of $\$ 100$ million although one source gives an estimate of $\$ 92$ million. The former is used here as the consensus estimate.

- Northridge (Calif.), January 17, 1994. NGDC-s lists this event as costing $\$ 40$ billion, using the figure published by the California Geological Survey (CAGS). EM-DAT estimates the event at $\$ 16.5$ billion and SHELDUS uses \$20 billion following the official U.S. Geologic Survey report (USGS 1996). Many news and internet sources cite numbers in the $\$ 12$ billion-\$15 billion range. Table 2.2 of the 1999 Economic Report of the President estimates total damages at $\$ 74.8$ billion in 1992 dollars (\$78.2 billion in 1994, Office of the President 1999 , p. 82). Finding no clearly definitive source, the average of the low (EM-DAT) and high (President's Economic Report) are used for an estimate of $\$ 47.35$ billion.

- Eureka/Arcata (Calif.), December 26, 1994. A low of $\$ 2.1$ million (EM-DAT) and high of \$5 million (NGDC) are cited. CSUH cites $\$ 5$ million but there is a lack of strong support for either number, so an average is used.

- Nisqually/Seattle metro area (Wash.), February 28, 2001. Although NGDC-s lists damages of $\$ 2$ billion and $\$ 4$ billion, most damage estimates for this earthquake, including the work of Beyers and Chang (2002) and Meszaros and Fiegener (2002), settle on $\$ 2$ billion as a conservative estimate.

- Mentasta Lake/Denali Fault (Alaska), November 3, 2002. Estimates range from \$20 million-\$56 million. News reports show a similar range so an average of the two is used.

- Paso Robles/San Simeon (Calif.), December 22, 2003. EMDAT cites \$200 million while NGDC and most other sources cite \$300 million. Report No. 04-02 of the California Seismic Safety Commission (dated May 5, 2004) reports, "FEMA, state and local officials estimate there were over \$239 million in direct losses." McEntire and Cope (2004) note, "Total financial losses along with the cost of debris removal and emergency protective measures amounted to $\$ 226,557,500$ for the entire county (County of San Luis Obispo 2004). These figures do not include state road systems and other damages or indirect losses/expenses." Since the \$200 million estimate is contradicted by strong evidence and the specific figures cited are minimum estimates, the $\$ 300$ million estimate is used.

\section{Appendix II. All Earthquakes with Known Recorded Damages}

See text for explanation of sources. "ACC" refers to the average, credible or consensus "middle" value chosen (see text and Appendix I). FIPS refers to the county code following the U.S. Census Bureau standard. When a CSA is used for the population factor (see text for further explanation) a FIPS code of 6901 denotes the SF CSA, 6902 denotes the LA CSA, and 53999 denotes the Seattle CSA. 


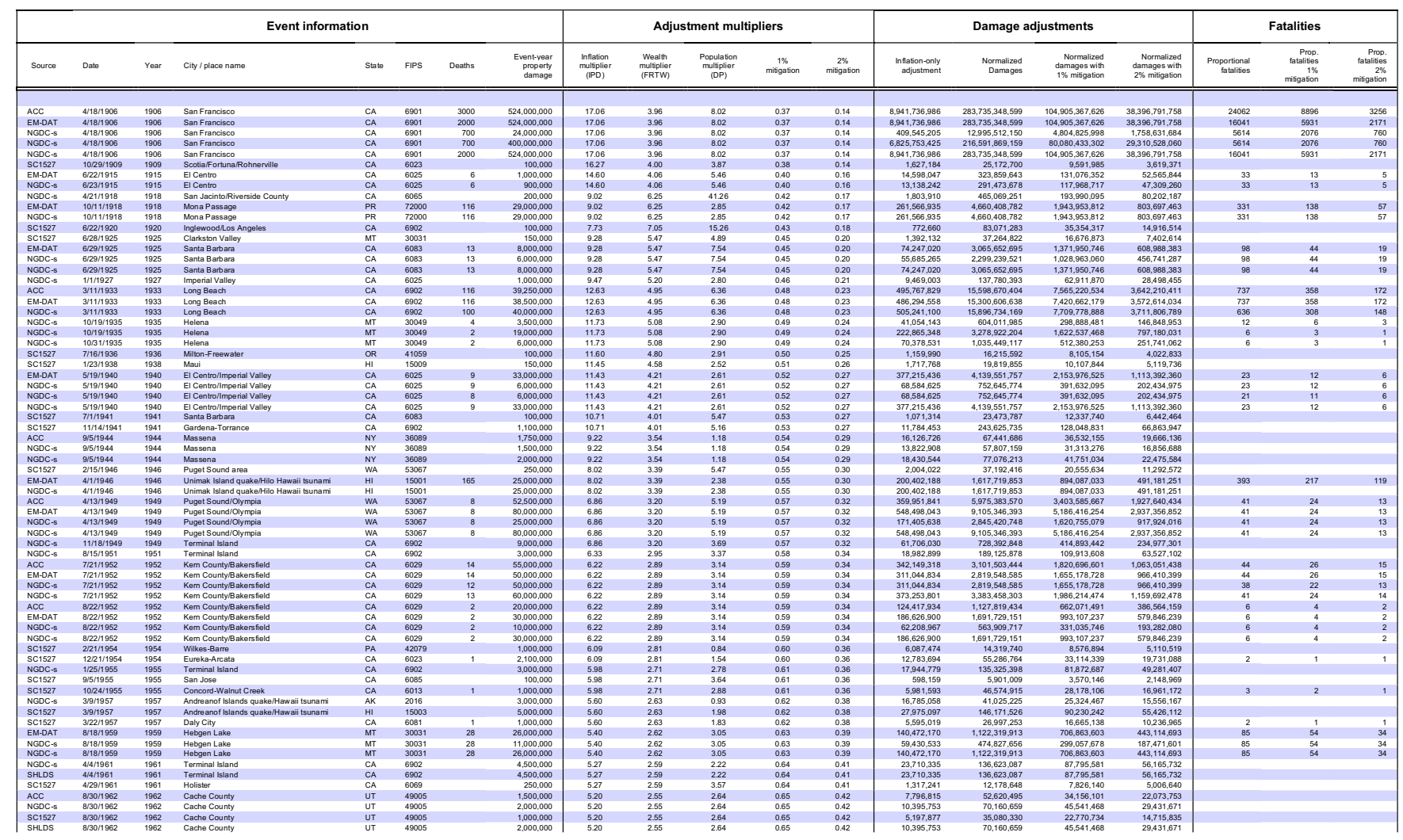
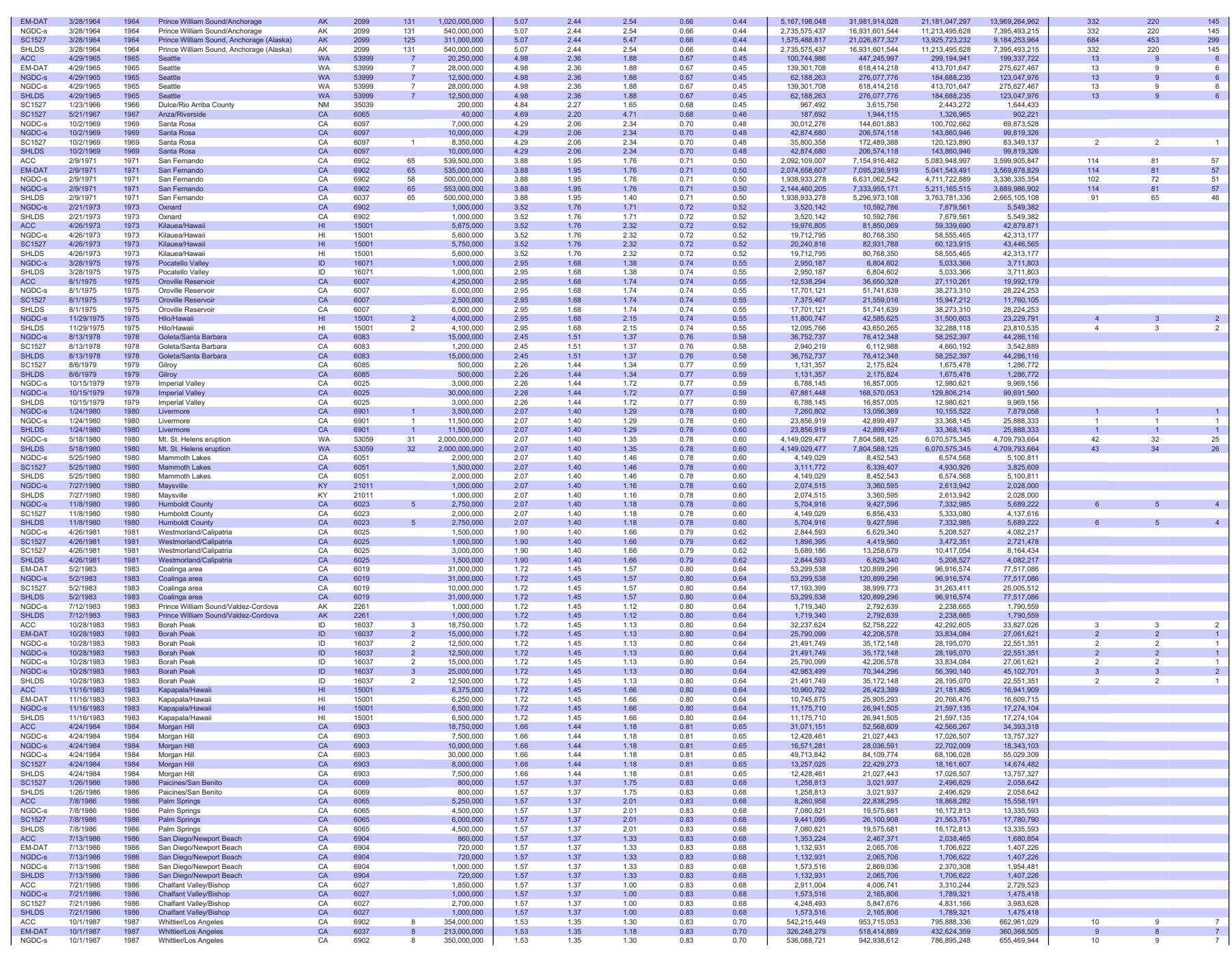


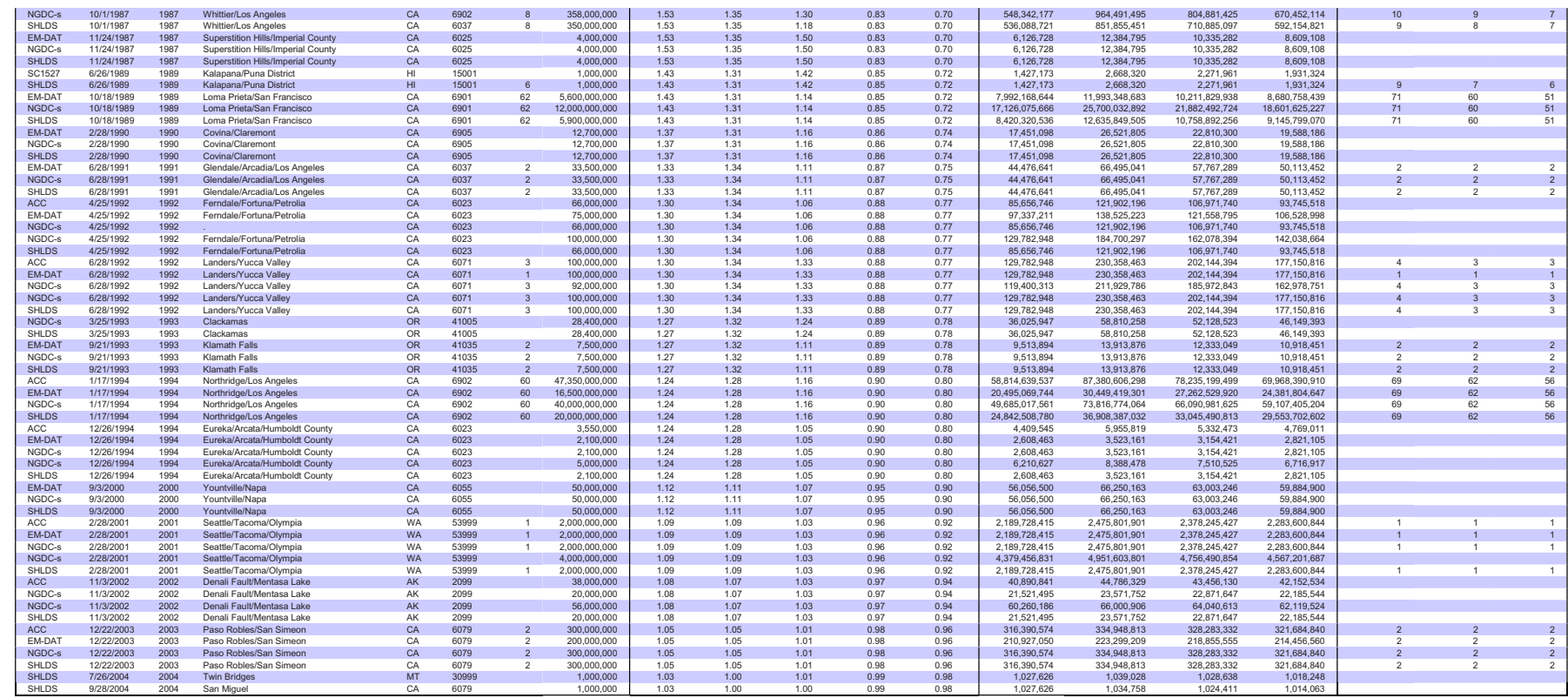

\section{Appendix III. Significant Earthquakes with No Damage Estimate}

The following is a list of events from Stover and Coffman (1993) with damage descriptions that imply that considerable economic losses, but for which no estimates are available. Events for which damage reports are confined to chimney collapses, broken windows and/or falling plaster are not included in the list. In general, events with a Modified Mercalli Intensity (MMI) of VIII probably caused damages in the hundreds of thousands to millions of dollars. Extreme events with MMI of IX or X are included even where they did not produce extensive damage due to occurrence in sparsely populated areas. The table is sorted by state and then by date.

\begin{tabular}{|c|c|c|c|c|c|}
\hline Date & Place & State & MMI & Magnitude & Comment \\
\hline Oct. 16,1947 & Fairbanks area & Alaska & VIII & $7.2 \mathrm{M}_{\mathrm{S}}$ & Extensive infrastructure damage reported. \\
\hline Oct. 3, 1954 & Kenai Peninsula & Alaska & VIII & $6.5 \mathrm{Unk}$ & Damage to buildings and infrastructure. \\
\hline Mar 9, 1957 & Andreanof Islands & Alaska & VIII & $8.1 \mathrm{M}_{\mathrm{S}}$ & $\begin{array}{l}\text { Hawaiian tsunami losses given in Appendix II. } \\
\text { Extensive damage also reported in Alaska, including } \\
\text { two bridges destroyed, but no loss estimates. }\end{array}$ \\
\hline Feb. 2, 1975 & Aleutian Islands & Alaska & IX & $7.4 \mathrm{M}_{\mathrm{S}}$ & $\begin{array}{l}\text { Severe damage on Shemya Island, home of an Air } \\
\text { Force base. }\end{array}$ \\
\hline Jul. 28, 1902 & Los Alamos/Santa Barbara County & Calif. & VIII & $5.4 \mathrm{M}_{\mathrm{La}}$ & Extensive damage from this and a 31-Jul aftershock. \\
\hline Aug. 3, 1903 & San Jose & Calif. & VII & $5.3 \mathrm{M}_{\mathrm{S}}$ & Many buildings damaged severely. \\
\hline Apr. 19, 1906 & Brawley/Imperial Valley & Calif. & VIII & $6+M_{S}$ & $\begin{array}{l}\text { Every building in Brawley damaged, minor damage } \\
\text { in four other towns. }\end{array}$ \\
\hline Mar. 10, 1922 & $\begin{array}{l}\text { Cholame Valley/ } \\
\text { San Luis Obispo County }\end{array}$ & Calif. & IX & $6.5 \mathrm{M}_{\mathrm{S}}$ & $\begin{array}{l}\text { Many houses severely damaged along the San } \\
\text { Andreas fault. }\end{array}$ \\
\hline Jan. 22, 1923 & Humboldt County & Calif. & VIII & $7.2 \mathrm{M}_{\mathrm{S}}$ & Houses damaged severely in three towns. \\
\hline Jun. 29, 1926 & Santa Barbara & Calif. & VII & $5.5 \mathrm{M}_{\mathrm{La}}$ & $\begin{array}{l}\text { Minor damages reported but one person killed by } \\
\text { falling brick. }\end{array}$ \\
\hline Oct. 22,1926 & Coastal Monterey County & Calif. & VII & $6.1 \mathrm{M}_{\mathrm{S}}$ & Considerable damage in the Monterey Bay region. \\
\hline Jun. 6, 1932 & West of Eureka, Humboldt County & Calif. & VIII & $6.4 \mathrm{M}_{\mathrm{S}}$ & $\begin{array}{l}\text { "Severe" property damage reported with one fatality } \\
\text { and numerous injuries. }\end{array}$ \\
\hline Dec. 14,1950 & Herlong/Lassen County & Calif. & VII & $5.6 \mathrm{M}_{\mathrm{L}}$ & Considerable structural damage in Herlong. \\
\hline Aug. 8, 1989 & $\begin{array}{l}\text { Redwood Estates/ } \\
\text { Santa Clara County }\end{array}$ & Calif. & VII & $5.4 \mathrm{M}_{\mathrm{L}}$ & $\begin{array}{l}\text { One fatality and moderate damage to many } \\
\text { structures. }\end{array}$ \\
\hline Apr. 10, 1967 & Denver-Boulder area & Colo. & VI & $4.3 \mathrm{M}_{\mathrm{n}}$ & $\begin{array}{l}\text { Minor damage reported, but spread widely throughout } \\
\text { metro region. }\end{array}$ \\
\hline Aug. 9, 1967 & Denver-Boulder area & Colo. & VII & $5.3 \mathrm{~m}_{\mathrm{b}}$ & Foundation damage on many buildings. \\
\hline Sept. 26, 1929 & Kona & Hiwaii & VII & $5.6 \mathrm{M}_{\mathrm{S}}$ & Houses and infrastructure damaged. \\
\hline Oct. 6, 1929 & Holualoa & Hiwaii & VII & $6.5 \mathrm{M}_{\mathrm{S}}$ & Extensive structural damage to residences and roads. \\
\hline Aug. 21, 1951 & Napoopoo & Hiwaii & VIII & $6.9 \mathrm{M}_{\mathrm{S}}$ & $\begin{array}{l}\text { Severe damage to residences, churches, schools and } \\
\text { infrastructure. }\end{array}$ \\
\hline
\end{tabular}




\begin{tabular}{|c|c|c|c|c|c|}
\hline Date & Place & State & MMI & Magnitude & Comment \\
\hline Oct. 3, 1915 & Pleasant Valley & Nev. & $X$ & $7.7 \mathrm{M}_{\mathrm{S}}$ & $\begin{array}{l}\text { Severe damage throughout a sparsely populated } \\
\text { region. }\end{array}$ \\
\hline Dec. 21,1932 & Cedar Mountain & Nev. & & $4.6 \mathrm{M}_{\mathrm{X}}$ & $\begin{array}{l}\text { Very strong earthquake in a then-sparsely populated } \\
\text { area. }\end{array}$ \\
\hline Jul. 6,1954 & Fallon-Stillwater & Nev. & IX & $6.8 \mathrm{M}_{\mathrm{L}}$ & $\begin{array}{l}\text { Severe damage in Fallon, otherwise area sparsely } \\
\text { populated at the time. }\end{array}$ \\
\hline Dec. 16,1954 & Dixie Valley-Fairview Peak & Nev. & $\mathrm{X}$ & $7.2 \mathrm{M}_{\mathrm{L}}$ & Major earthquake in a sparsely populated area. \\
\hline Jul. 12, 1906 & Socorro area & N.M. & VII & & $\begin{array}{l}\text { Extensive, severe damage to business district. } \\
\text { Aftershocks of Jul. } 16 \text { and Nov. } 15 \text { added to the } \\
\text { damage. }\end{array}$ \\
\hline Aug. 12, 1929 & Attica/Wyoming County & N.Y. & VIII & $5.2 \mathrm{M}_{\mathrm{N}}$ & $\begin{array}{l}\text { Extensive building damage and some infrastructure } \\
\text { damage. }\end{array}$ \\
\hline Aug. 16, 1931 & Valentine/Jeff Davis County & Tex. & VIII & $5.8 \mathrm{M}_{\mathrm{N}}$ & $\begin{array}{l}\text { All buildings in Valentine except wood-frame houses } \\
\text { severely damaged. }\end{array}$ \\
\hline Mar. 12, 1934 & Kosmo/Box Elder County & Utah & VIII & $6.6 \mathrm{M}_{\mathrm{S}}$ & Sparsely populated area; killed two. \\
\hline
\end{tabular}

Note: $M M I=$ modified Mercalli Intensity (I-XII); $\mathrm{M}_{\mathrm{S}}=$ surface-wave magnitude; $\mathrm{m}_{b}=$ body-wave magnitude; $\mathrm{M}_{L}=$ local (Richter) magnitude (Western U.S.); $\mathrm{M}_{L a}=$ local (California) magnitude; $\mathrm{M}_{N}=$ local and regional magnitude (Eastern U.S.); and Unk=unknown computational method.

\section{References}

Algermissen, S. T., Rinehart, W., and Dewey, J. W. (1972). "A study of earthquake losses in the San Francisco Bay Area-Data and analysis." Environmental Research Laboratories, Boulder, Colo., 220.

Beyers, W. B., and Chang, S. E. (2002). "Economic impacts of the Nisqually earthquake on households in the Puget Sound Region." North American Regional Science Meetings, North American Regional Science Council, San Juan, Puerto Rico.

Bouwer, L. M., Crompton, R. P., Faust, E., Höppe, P., and Pielke, R. A., Jr. (2007). "Confronting disaster losses." Science, 318(5851), 753.

Brooks, H. E., and Doswell, C. A. I. (2001). "Normalized damage from major tornadoes in the United States: 1890-1999." Weather Forecast., 16(2), 168-176.

California Geological Survey (CAGS). (2009). 〈http://www.consrv.ca. gov:80/cgs/rghm/quakes/pages/eq_chron.aspx $\rangle$ (Jan. 30, 2009).

Coffman, J. L., von Hake, C. A., and Stover, C. W. (1982). "Earthquake history of the United States, Revised Edition (through 1970), Reprinted 1982 with supplement (1971-80)." Pub. 41-1, U.S. Dept. of Commerce, Boulder, Colo., 258.

Collins, D. J., and Lowe, S. P. (2001). "A macro validation dataset for U.S. hurricane models." Casualty Actuarial Society Forum, Casualty Actuarial Society, Arlington, Va.

Congressional Budget Office (CBO). (2007). "Potential cost savings from the pre-disaster mitigation program.” Pub. No. 2926, U.S. Congress, Washington, D.C., 10.

Cutter, S. L., and Emrich, C. (2005). "Are natural hazards and disaster losses in the U.S. increasing?" EOS Trans. Am. Geophys. Union, 86(41), 381, 388-389.

Downton, M. W., and Pielke, J. R. A. (2005). "How accurate are disaster loss data? The case of U.S. flood damage." Natural Hazards, 35(2), 211-228.

Dunbar, P. K. (1985). "Earthquake intensity database." National Geophysical Data Center, National Oceanographic and Atmospheric Administration, 〈http://ngdc.noaa.gov/seg/hazard/int_srch.shtml〉 (Mar. 14, 2006).

Dunbar, P. K., Lockridge, P. A., and Whitewide, L. S. (2006). "Catalog of significant earthquakes 2150 B.C. to the present." National Geophysical Data Center, National Oceanographic and Atmospheric Administration, 〈http://ngdc.noaa.gov/seg/hazard/sigintro.shtml $\rangle$ (Mar. 14, 2006).

EM-DAT. (2006). "EM-DAT: The OFDA/CRED international disaster database." Université Catholique de Louvain, 〈http://www.em-dat.net〉 (Mar. 23, 2006).

FEMA. (2001). "HAZUS99 estimated annualized earthquake losses for the United States." FEMA 366, Federal Emergency Management Agency, Washington, D.C., 32.

Haas, J. E., Kates, R. W., and Bowden, M. J. (1977). "Reconstruction following disaster.” MIT Press, Cambridge, Mass., 366.

Hansen, G., and Condon, E. (1989). "Denial of disaster: The untold story and photographs of the San Francisco earthquake and fire of 1906." Cameron \& Company, San Francisco, 160.

Hansen, Z. K., and Libecap, G. D. (2004). "Small farms, externalities, and the dust bowl of the 1930s." J. Polit. Econ., 112(3), 665-694.

Hazards Research Lab. (2006). "The spatial hazard events and losses database for the United States, v. 4.1." Hazards Research Lab., Univ. of South Carolina, 〈http://go2.cla.sc.edu/sheldus〉 (Apr. 11, 2006).

Hodgson, E. A. (1945). "The Cornwall-Massena earthquake, September 5, 1944 (with Plates II-V).” J. R. Astron. Soc. Can., 39(1), 5-13.

Johnston, L. D., and Williamson, S. H. (2006). "The annual real and nominal GDP for the United States, 1790-present." Economic History Services, 〈http://eh.net/hmit/gdp/〉 (Apr. 1, 2006).

Katz, R. W. (2002). "Stochastic modeling of hurricane damage." J. Appl. Meteorol., 41(7), 754-762.

Kircher, C. A., Seligson, H. A., Bouabid, J., and Morrow, G. C. (2006a). "When the big one strikes again-Estimated losses due to a repeat of the 1906 San Francisco earthquake." Earthquake Spectra, 22(S2), S297-S339.

Kircher, C. A., Whitman, R. V., and Holmes, W. T. (2006b). "HAZUS earthquake loss estimation methods." Nat. Hazards Rev., 7(2), 45-59.

Lawson, A. C. (1908). "The California earthquake of April 18, 1906, Vol. 1." Publication No. 87, Vol. I, Parts I \& II, Carnegie Institution of Washington, Washington, D.C., 451.

McEntire, D. A., and Cope, J. (2004). "Damage assessment after the Paso Robles (San Simeon, California) Earthquake: Lessons for emergency management." Rep. No. Quick Response Research \#166, Natural Hazards Center, Univ. of Colorado.

Meade, C., and Abbott, M. (2003). "Assessing federal research and development for hazard loss reduction.” MR-1734-OSTP, RAND Science and Technology Policy Institute, Santa Monica, Calif., 65.

Meszaros, J., and Fiegener, M. (2002). "Effects of the 2001 Nisqually earthquake on small businesses in Washington State." Economic Development Administration, Seattle, 43.

Miller, R. K. (1979). "The Santa Barbara earthquake of 13 August, 1978." Earthquake Eng. Struct. Dyn., 7(5), 491-506.

Munich, R. (2001). World of natural hazards (CD-ROM), Munich Re Group, Munich, Germany.

Munich, R. (2006). "The 1906 earthquake and Hurricane Katrina: Similarities and differences-Implications for the insurance industry." 302-04961, Geo Risks Research, Munich Re, Munich, Germany, 16.

National Research Council (NRC). (1999). "The impacts of natural disas- 
ters: A framework for loss estimation." Committee on Assessing the Costs of Natural Disasters, Washington, D.C., 68.

Noson, L. L., Qamar, A., and Thorsen, G. W. (1988). "Washington State earthquake hazards." Information Circular 85, Washington Division of Geology and Earth Resources, Olympia, Washington, 77.

Odell, K. A., and Weidenmier, M. D. (2004). "Real shock, monetary aftershock: The 1906 San Francisco earthquake and the panic of 1907." J. Econ. Hist., 64(4), 1002-1027.

Office of the President. (1999). Economic Report of the President, United States Government Printing Office, Washington, D.C., 454.

Parker, R. P., and Triplett, J. E. (1995). "Preview of the comprehensive revision of the national income and product accounts: Recognition of government investment and a new methodology for calculating depreciation." Survey of Current Business, 75 (July), 33-41.

Pielke, J. R. A., Crompton, R., Faust, E., Gratz, J., Lonfat, M., Ye, Q., and Raghavan, S. (2006). "Factors contributing to human and economic losses." 6th WMO Int. Workshop on Tropical Cyclones, World Meteorological Organization, San José, Costa Rica.

Pielke, R., and Carbone, R. E. (2002). "Weather impacts, forecasts, and policy: An integrated perspective." Bull. Am. Meteorol. Soc., 83(3), 393-403.

Pielke, R. A., Jr., Gratz, J., Landsea, C. W., Collins, D., Saunders, M. A., and Musulin, R. (2008). "Normalized hurricane damages in the United States: 1900-2005." Nat. Hazards Rev., 9(1), 29-42.

Pielke, R. A., Jr., and Landsea, C. (1998). "Normalized hurricane damages in the United States: 1925-95." Weather Forecast., 13(3), 621631.

Pielke, R. A., Jr., Rubiera, J., Landsea, C., Fernández, M. L., and Klein, R. (2003). "Hurricane vulnerability in Latin America and the Caribbean: Normalized damage and loss potentials." Nat. Hazards Rev., 4(3), 101-114.

Raghavan, S., and Rajesh, S. (2003). "Trends in tropical cyclone impact: A study in Andhra Pradesh, India." Bull. Am. Meteorol. Soc., 84(5), 635-644.

Steinbrugge, K. V. (1982). Earthquakes, volcanoes, and tsunamis: An anatomy of hazards, Skandia America Group, New York, 392.

Stover, C. W., and Coffman, J. L. (1993). "Seismicity of the United States, 1568-1989 (revised)." USGS Professional Paper 1527, United States Geological Survey, Washington, D.C., 427.

USGS. (1996). "USGS response to an urban earthquake: Northridge '94." Open-File Rep. 96-263, U.S. Dept. of the Interior, U.S. Geologic Survey, Denver, 78.

Wood, H. O., and Neumann, F. (1931). "Modified Mercalli intensity scale of 1931." Bull. Seismol. Soc. Am., 21(4), 277-283. 